\title{
Testing the performance of state-of-the-art dust emission schemes using D04Models field data
}

\author{
K. Haustein ${ }^{1}$, R. Washington ${ }^{1}$, J. King ${ }^{1}$, G. Wiggs ${ }^{1}$, D. S. G. Thomas ${ }^{1}$, F. D. Eckardt ${ }^{2}$, R. G. Bryant ${ }^{3}$, and L. Menut ${ }^{4}$ \\ ${ }^{1}$ School of Geography and the Environment, University of Oxford, Oxford, UK \\ ${ }^{2}$ University of Cape Town, Environmental and Geographical Science, Cape Town, South Africa \\ ${ }^{3}$ Department of Geography, University of Sheffield, Sheffield, UK \\ ${ }^{4}$ Laboratoire de Météorologie Dynamique, Ecole Polytechnique, Palaiseau, France
}

Correspondence to: K. Haustein (karsten.haustein@ouce.ox.ac.uk)

Received: 4 August 2014 - Published in Geosci. Model Dev. Discuss.: 3 September 2014

Revised: 19 January 2015 - Accepted: 23 January 2015 - Published: 19 February 2015

\begin{abstract}
Within the framework of the Dust Observations for Models (DO4Models) project, the performance of three commonly used dust emission schemes is investigated in this paper using a box model environment. We constrain the model with field data (surface and dust particle properties as well as meteorological parameters) obtained from a dry lake bed with a crusted surface in Botswana during a 3 month period in 2011. Our box model results suggest that all schemes fail to reproduce the observed horizontal dust flux. They overestimate the magnitude of the flux by several orders of magnitude. The discrepancy is much smaller for the vertical dust emission flux, albeit still overestimated by up to an order of magnitude. The key parameter for this mismatch is the surface crusting which limits the availability of erosive material, even at higher wind speeds. The second-most important parameter is the soil size distribution. Direct dust entrainment was inferred to be important for several dust events, which explains the smaller gap between modelled and measured vertical dust fluxes. We conclude that both features, crusted surfaces and direct entrainment, need to be incorporated into dust emission schemes in order to represent the entire spectra of source processes. We also conclude that soil moisture exerts a key control on the threshold shear velocity and hence the emission threshold of dust in the model. In the field, the state of the crust is the controlling mechanism for dust emission. Although the crust is related to the soil moisture content to some extent, we are not as yet able to deduce a robust correlation between state of crust and soil moisture.
\end{abstract}

\section{Introduction}

Atmospheric mineral dust is the dominant aerosol species in terms of mass (Andreae, 1996; Textor et al., 2006), yet it is one of the major sources of uncertainty in the climate system (Forster et al., 2007; Boucher et al., 2013) despite recent efforts to reduce these uncertainties from a remote sensing (Ginoux et al., 2010, 2012; Ashpole and Washington, 2012; Brindley et al., 2012), physico-chemical (Redmond et al., 2010; Formenti et al., 2011), or modelling point of view (Huneeus et al., 2011; Knippertz and Todd, 2012; Klose and Shao, 2012). Numerical models are a key tool for predicting weather and climate. Given the interaction between mineral dust and the climate system, e.g. radiation (Pérez et al., 2006), clouds (Bangert et al., 2012), and weather systems such as tropical cyclones (Evan et al., 2006), it is important for models to simulate the dust cycle well. Key elements of model dust emission schemes are largely based on empirical data from wind tunnel experiments. Their emitted dust loadings have often been tuned to match global (Pérez et al., 2011; Huneeus et al., 2011) or regional (Laurent et al., 2006; Heinold et al., 2009; Haustein et al., 2012) satellite or in situ dust data (Holben et al., 1998; Remer et al., 2002; Kahn et al., 2005) rather than attending to the efficacy of the emissions in key regions. None of the currently existing schemes has been thoroughly assessed with field data at the scale of a numerical model grid box.

Prompted by this apparent gap in appropriate data with which to evaluate numerical model dust emission schemes, DO4Models aims to provide dust source-area processed 
data tailored to regional climate model grid-box resolution $(12 \mathrm{~km} \times 12 \mathrm{~km})$ in order to test the performance of three dust emission schemes. These data have been obtained from a remote source area, Sua Pan, Botswana, undisturbed by background dust aerosol. In this paper we report on the characteristics of three emission schemes and quantitatively evaluate their performance at process level.

Using a box model approach and DO4Models field campaign data from 2011, we first quantify the magnitude and frequency of the simulated dust emission fluxes by comparing them with observed fluxes at the field sites. Three stateof-the-art schemes are employed: Marticorena and Bergametti (1995) (hereinafter MB95), the scheme of Alfaro and Gomes (2001) (AG01), and that of Shao (2004) (SH04). Secondly, we examine the impact of three sand transport formulations upon the simulated dust fluxes: the models of Owen (1964) (OW64), Lettau and Lettau (1978) (LL78), and Marticorena and Bergametti (1995) (which itself is based on White, 1979). These formulations predict a range of sand transport rates that vary by an order of magnitude and eventually control the dust production of the model as discussed and illustrated in Shao (2008) (their Fig. 6.9) and Sherman and $\mathrm{Li}$ (2012) (their Fig. 4). Thirdly, we test the impact the input parameters have on the sandblasting mass efficiency $\alpha$ (vertical-to-horizontal mass-flux ratio) and the threshold friction velocity $u_{* \text { thr }}$. The analysis is associated with an assessment of the box model performance as a function of surface roughness length, soil moisture content, and soil particle size distribution. The sensitivity of the simulated emission fluxes to observed soil and surface properties is discussed in the context of apparent model mismatches. Critical model components responsible for the discrepancies are identified.

The background to state-of-the-art dust emission schemes and an introduction of the observational data obtained during the field campaign are given in Sect. 2. The parameterisations used in the newly developed box model are introduced in Sects. 3.1-3.3, including the model evaluation strategy (Sect. 3.4). We analyse the model performance in Sects. 4.14.3 and discuss their implications in Sect. 4.4. Our findings are summarised in Sect. 5.

\section{Background}

The dust emission process is commonly described by three major mechanisms: dust emission by (1) aerodynamic lift, by (2) saltation bombardment (sandblasting), and by (3) disintegration of aggregates (auto-abrasion) as illustrated in Shao et al. (2011b). Several parameterisation schemes have been developed to describe these mechanisms (e.g. Marticorena and Bergametti, 1995; Shao and Lu, 2000; Alfaro and Gomes, 2001; Shao, 2004). See Darmenova et al. (2009) for a comprehensive review. Auto-abrasion is considered only by Shao (2004). Typically, each scheme parameterises the following quantities in separate steps or modules: (a) the threshold friction velocity for particle movement, (b) the horizontal saltation flux (defined as the vertical integral of the streamwise particle flux density) which describes the motion of saltating particles, and (c) the vertically emitted dust flux (defined as the emitted dust mass concentration per unit area and time) which determines the dust loading in the first model layer.

The threshold friction velocity, defined as the minimum friction velocity required to initiate the motion of soil grains, is specified over a smooth and dry surface $\left(u_{* \text { dry }}\right)$, requiring a drag partition correction to account for roughness elements at the surface, and a moisture correction to reflect moisture content in the soil which acts to inhibit the emissions. The saltation flux is proportional to the shear velocity, represented by a large array of parameterisation options (Sherman and $\mathrm{Li}, 2012$ ). The smooth threshold friction velocity, the saltation flux as well as the vertical emission flux are also functions of the size distribution and chemical composition of the soil particles (Kang et al., 2011).

Field data against which to test model output were gathered by the Dust Observations for Models (DO4Models) field campaign between 24 July and 14 October 2011. This campaign was focused on a $12 \mathrm{~km}^{2}$ measurement grid at Sua Pan in Botswana $\left(20.55^{\circ} \mathrm{S}\right.$ and $\left.25.95^{\circ} \mathrm{E}\right)$. Sua Pan is one of southern Africa's most important aeolian dust source areas (Bryant et al., 2007) and, as part of the $3400 \mathrm{~km}^{2}$ Makgadikgadi pan complex, it experiences ephemeral flooding of its surface (Eckardt et al., 2008). This flooding results in the development of a highly uneven polygonal salt crust of varying morphology and in various states of formation and degradation. As such the crust presents a surface which is highly variable and dynamic in both roughness and erodibility (Nield et al., 2013, 2015), with subsequent impact on the distribution of sites of aeolian dust emission. Such a surface presents a significant challenge for dust emission schemes as most are not explicitly developed for crusted surfaces as they can be found in many dust source regions worldwide (Nickling and Gillies, 1993; Rice et al., 1996; Ishizuka et al., 2008; Washington et al., 2009). Sua Pan has been chosen for this field campaign because of its remote situation from other major sources, which allows for an undisturbed characterisation of the emitted dust, which is particularly relevant for the estimation of the vertical dust flux.

Our field measurement arrays consisted of 11 meteorological stations distributed throughout the grid located within zones of differing surface characteristics, as interpreted from remote sensing imagery (Fig. 1). Each station is identified by a label representing its relative horizontal $(\mathrm{A}-\mathrm{L})$ and vertical (1-12) position within the $12 \mathrm{~km}^{2}$ grid. Each site was equipped with an anemometer mast measuring wind velocity at heights of $0.25,0.47,0.89,1.68,3.18$, and $6.0 \mathrm{~m}$ (AWS, MET/MET+ sites). Wind velocity data were averaged over a 1 min period to allow calculation of shear velocity $\left(u_{*}\right)$ and aerodynamic roughness $\left(z_{0}\right)$. A Sensit mass erosion monitor was installed on the surface at each site to provide $1 \mathrm{~min}$ 
Table 1. Minimally and fully disturbed soil size distribution for each field site at Sua Pan. The mass fraction (in percent) for each parent soil type is given. FMS is fine/medium sand and CS is coarse sand. (m) refers to minimally disturbed and (f) to fully disturbed soil. The non-emissive crust sample is used instead. The two right-hand columns are the average surface roughness $\left(\varnothing z_{0}\right.$ in $\left.\mathrm{cm}\right)$ and soil moisture content $\left(\varnothing w\right.$ in $\left.\mathrm{m}^{3} \mathrm{~m}^{-3}\right)$ at each site and averaged over the grid.

\begin{tabular}{lccccccccccc}
\hline Site & Type & Clay $(\mathrm{m})$ & Silt $(\mathrm{m})$ & FMS $(\mathrm{m})$ & CS $(\mathrm{m})$ & Clay (f) & Silt (f) & FMS (f) & CS (f) & $\varnothing z_{0}$ & $\varnothing w$ \\
\hline B3 & MET+ & 0.0 & 22.3 & 52.4 & 25.3 & 10.7 & 63.5 & 25.7 & 0.1 & 0.236 & 0.060 \\
B7 & AWS & 0.0 & 8.8 & 36.7 & 54.5 & 10.1 & 72.7 & 17.1 & 0.1 & 0.200 & 0.151 \\
D2 & MET & 0.0 & 4.6 & 24.6 & 70.7 & 13.9 & 74.3 & 11.7 & 0.1 & NA & NA \\
D5 & MET+ & 0.0 & 13.2 & 51.2 & 35.6 & 10.2 & 68.2 & 21.4 & 0.1 & 0.291 & 0.147 \\
D10 & MET+ & 0.0 & 14.4 & 48.0 & 37.5 & 11.6 & 68.6 & 19.1 & 0.7 & 0.292 & 0.040 \\
G2 & MET+ & 0.0 & 20.8 & 67.0 & 12.1 & 6.6 & 60.5 & 32.9 & 0.0 & 0.293 & 0.077 \\
G6 & AWS & 0.0 & 14.7 & 55.7 & 29.6 & 11.4 & 76.9 & 10.7 & 0.1 & 0.391 & 0.113 \\
I4 & MET+ & 0.0 & 21.0 & 72.6 & 6.5 & 8.6 & 60.6 & 29.4 & 1.5 & 0.230 & 0.072 \\
I8 & MET & 0.0 & 6.2 & 45.6 & 48.2 & 10.8 & 79.7 & 9.3 & 0.2 & NA & NA \\
J11 & MET+ & 0.0 & 3.6 & 32.0 & 64.4 & 9.3 & 74.1 & 15.7 & 0.1 & 0.108 & 0.166 \\
L5 & AWS & 0.0 & 4.9 & 20.9 & 74.2 & 9.4 & 63.4 & 27.2 & 0.0 & 0.006 & 0.168 \\
\hline ALL & $\varnothing$ & 0.0 & 12.8 & 48.0 & 39.1 & 10.1 & 67.8 & 21.7 & 0.4 & 0.175 & 0.096 \\
\hline
\end{tabular}

* In a few cases the fluff material could not be sampled.

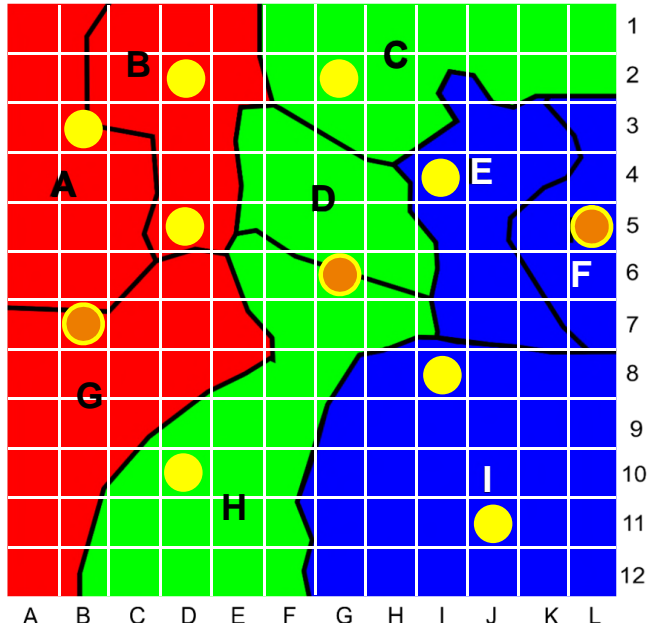

Figure 1. The Sua Pan $12 \times 12 \mathrm{~km}$ grid with three AWS sites (orange dots) and another eight MET/MET + sites (yellow dots). Through combined use of a range of remote sensing data, three zones which allowed for a distinct interpretation in terms of crust types and potential for erodibility were selected. The colours indicate different soil conditions present throughout the campaign. Red: well-developed salt crust which would not be easily erodible $(\mathrm{A} / \mathrm{B} / \mathrm{G})$; green: intermediary salt crusts that were either not as well developed as in A, B and G or significantly less moist than in E, F and I; blue: relatively moist surfaces that were most likely to have been either re-set (dissolved/reworked) or degraded (partially dissolved/reworked) by recent flooding and dilute inflow. The relatively high moisture content of these surfaces would render them relatively non-erodible.

resolution data on sand saltation activity (within $5 \mathrm{~cm}$ above the surface) and BSNE (Big Spring Number Eight) dust traps (Fryrear, 1986) were positioned at heights of $0.25,0.47,0.89$, and $1.89 \mathrm{~m}$ to determine the average horizontal sediment flux over periods of 14 days. Data from the BSNEs allowed for the estimation of the integrated vertical flux and are used to convert the Sensit frequency data into a horizontal mass flux. At nine of the meteorological stations (AWS, MET+ sites), DustTrak DRX aerosol monitors were installed at a height of $3.18 \mathrm{~m}$ to record concentrations of $\mathrm{PM}_{1}, \mathrm{PM}_{2.5}, \mathrm{PM}_{10}$, and $\mathrm{PM}_{\text {tot }}$ particles at 2 min temporal resolution. Thetaprobe moisture sensors were installed in the pan surface at each site to measure moisture content integrated across depths of 0-3 and 9-12 cm. Automatic weather stations were deployed at three AWS sites. Two CIMEL sun photometers were deployed inside (at the centre) and outside (upwind) of the grid in order to obtain the atmospheric aerosol optical depth (AOD) and the Angström exponent. Finally, the threshold shear velocity for dust emission was assessed at 98 locations across the measurement grid using a Pi-SWERL wind tunnel (King et al., 2011), providing a potential dust source map for the grid.

Surface sediment at each site was sampled and returned to Oxford for grain size analysis using a Malvern laser granulometer. This was used in "wet" fully dispersed mode (assumed to represent the dust in suspension), and also in "dry" minimally dispersed mode using an air dispersion unit (which maintains and measures any particle agglomerates which might be assumed to comprise the saltation flux). The sediment sampled included the surface crust $(0-0.5 \mathrm{~cm}$ thick, where present), a dry "fluff" layer often present beneath the crust (1-3 cm thick), and a deeper clay soil unit beneath (see Table 1).

To drive the box model, we are using roughness length data $\left(z_{0}\right)$ which were assumed to be constant in each direction for three consecutive days, derived from 10 min wind 
observations. Observed gravimetric soil moisture content at $0-3 \mathrm{~cm}$ depth $(w)$ which closely matches the soil moisture provided by atmospheric models in their uppermost soil layer is used. For the purpose of grid-wide box model comparison, we take the arithmetic mean values of $z_{0}$ and $w$ in 2011 (Table 1). Also, the minimally and the fully disturbed soil size distributions are used (Table 1). For the direct model comparison, the shear velocity $\left(u_{*}\right)$ is used. It is obtained using the measured wind profile data and the surface roughness data. The saltation flux $Q_{\mathrm{OBS}}$ is assumed to be proportional to the Sensit counts, calibrated using the BSNE data. The vertical distribution of the dust mass collected in the BSNEs follows an exponential function which is in good agreement with empirical considerations. The total vertical dust flux $\left(F_{\mathrm{OBS}}\right)$ is estimated following the procedure of Gillette (1974) from the DustTrak concentration data in the following way: $F_{\mathrm{OBS}}=\left(\mathrm{PM}_{\mathrm{tot}}-\mathrm{PM}_{2.5}\right) \cdot u_{*}^{\prime}$. $\mathrm{PM}_{\mathrm{tot}}$ is the total and $\mathrm{PM}_{2.5}$ is the particulate matter smaller than $2.5 \mu \mathrm{m}$ in diameter. The fluctuating component of the shear velocity is calculated as $u_{*}^{\prime}=u_{*}-\bar{u}_{*}$, with $\bar{u}_{*}$ as the mean shear velocity at each site during the campaign period. As we are interested in the positive dust flux, $F_{\mathrm{OBS}}$ is considered as contributing emission flux only if $F_{\mathrm{OBS}, t}-F_{\mathrm{OBS}, t-1}>\sigma$, with $\sigma$ as the standard deviation of $F_{\mathrm{OBS}}$. The time interval $\Delta t$ is $2 \mathrm{~min}$ for all parameters.

The deduced fluxes are not a direct flux measurement. Both $Q_{\mathrm{OBS}}$ and $F_{\mathrm{OBS}}$ are subject to uncertainties. The uncertainty associated with $Q_{\mathrm{OBS}}$ is likely quite high relative to the value for most of the site measurements due to the very limited quantity measured by the BSNE during each collection interval. However, for the sites that experienced relatively higher amounts of $Q_{\mathrm{OBS}}$, this uncertainty is greatly reduced because more mass was collected at each collection interval to calibrate the Sensit record. The $F_{\mathrm{OBS}}$ uncertainty is rooted in the error of the DustTrak and the flux calculation methodology. The DustTrak used in this study has shown to have very small errors $(\sim 10 \%)$ for $\mathrm{PM}_{2.5}$ values when compared with a TEOM and reasonable error $(\sim 15 \%)$ for $\mathrm{PM}_{\text {tot }}$ when compared with a condensation particle counter (Wang et al., 2009). When combined with the high measurement frequency capabilities of the DustTrak, this instrument outperforms most other nephelometers for $\mathrm{PM}_{10}$ measurements and far exceeds the performance of aerosol optical particle counters (Wang et al., 2009; Watson et al., 2011). The vertical dust flux calculation methodology will underestimate the total dust flux when compared to theoretical estimates from a removal of both the $\mathrm{PM}_{2.5}$ mass fraction and the very highfrequency wind fluctuations. This bias then minimises the likelihood of including dust emission fluxes that are only entraining $\mathrm{PM}_{2.5}$ particles (at $3.18 \mathrm{~m}$ in height) or that are associated with smaller fluctuations in $u_{*}$. The former is of minimal concern, as most dust emission mass fluxes from crusted surfaces contain a larger portion of $\mathrm{PM}_{10}$ than $\mathrm{PM}_{2.5}$ (Shao et al., 2011a). The latter bias does increase the uncertainty in the calculated $F_{\mathrm{OBS}}$ as it omits mechanisms such as dust dev- ils that aerodynamically entrain dust particles through thermal instabilities. Although this is an important mechanism for dust uplift from crusted sources, it is not a process captured by the dust emission schemes tested in this paper and therefore introduces minimal uncertainty in the comparative results.

Since no severe dust event could be observed in the course of the 2011 campaign period, difficulties arise in establishing a relationship between $u_{*}$ and the fluxes over a wider range of values. We therefore cannot rule out an unexpected increase in the emission flux which deviates from theoretical considerations. We have however high confidence in the identification of the emission signal resulting from specific wind events.

\section{Box model development}

This paper investigates a newly constructed set of box models which can either be run with synthetic data to test the range of potential changes in dust emission due to individual model parameters, or which can be driven with observational data. Input parameters are the shear velocity $\left(u_{*}\right)$, the surface roughness $\left(z_{0}\right)$, the soil moisture content $(w)$ and the mass size distribution of the soil $\left(\Delta D_{p}\right)$. Four parent particle size populations are considered for all simulations (diameter range in parentheses): clay $(0-2 \mu \mathrm{m})$, silt $(2-50 \mu \mathrm{m})$, fine/medium sand (FMS; 50-500 $\mu \mathrm{m}$ ), and coarse sand (CS; $500-1000 \mu \mathrm{m})$. They cover the typical size range and chemical composition of dust particles in desert regions. In regional and global numerical dust models, these four populations are converted into soil texture classes (Tegen et al., 2002) in order to match the information provided by the global soil data sets (e.g. FAO-UNESCO, 1974; Zobler, 1986, 1999).

\subsection{The Marticorena scheme}

The MB95 emission scheme as implemented in the box model starts with the calculation of the semi-empirically derived threshold friction velocity over smooth surfaces $\left(u_{* \text { dry }}\right)$ (Iversen and White, 1982; Greeley and Iversen, 1985). Required input parameters are the air density $\left(\rho_{\text {air }}\right)$, the soil particle density $\left(\rho_{p}=2.5 \mathrm{~g} \mathrm{~m}^{-3}\right.$ for clay; $2.65 \mathrm{~g} \mathrm{~m}^{-3}$ for the rest), and the median particle diameter $\left(D_{p}\right)$. The exact empirical formulation for $u_{* \operatorname{dry}}\left(D_{p}\right)$ is given in box 1a in Fig. 1 in Darmenova et al. (2009).

The calculation of the threshold velocity $u_{* \text { thr }}$ over a rough surface with potentially wet soil conditions requires the application of a moisture (Fécan et al., 1999) $(H)$ and roughness correction (MacKinnon et al., 2004; Marticorena et al., 2006) ( $R$ ) for $u_{* \text { dry }}$ :

$$
u_{* \operatorname{thr}}\left(D_{p}, z_{0}, w\right)=\frac{u_{* \mathrm{dry}}\left(D_{p}\right)}{R\left(z_{0}\right)} \cdot H(w),
$$


with

$$
R\left(z_{0}\right)=1-\frac{\ln \left(\frac{z_{0}}{z_{0 s}}\right)}{\ln \left(0.7 \cdot\left(\frac{c_{\mathrm{MB} 95 / \mathrm{McK} 04}}{z_{0 s}}\right)^{0.8}\right)}
$$

and

$$
H(w)=\left\{\begin{array}{ll}
\left(1+1.21 \cdot\left(w-w^{\prime}\right)^{0.68}\right)^{0.5} & w>w^{\prime} \\
1 & w<w^{\prime}
\end{array} .\right.
$$

The roughness correction after MacKinnon et al. (2004) (McK04) was originally developed for vegetated terrain, but has the advantage of spanning a wider range of roughness values, which turns out to be important in our case, as discussed in Sect. 4.2. The constant $c_{\mathrm{McK} 04}$ is assumed to be $122.5 \mathrm{~m}$ and the constant $c_{\mathrm{MB} 95}$ is set to $0.1 \mathrm{~m}$ (Marticorena et al., 2006). Either $c_{\mathrm{MB} 95}$ or $c_{\mathrm{McK} 04}$ can be used in Eq. (2). Both corrections follow the concept of a drag partition between mobile sand particles at the ground (smooth roughness $z_{0 s}$ ) and larger non-erodible roughness elements (aeolian roughness $z_{0}$ ). For a more detailed discussion on the concept of the characteristic roughness length scales, we refer the reader to Menut et al. (2013). We treat the localscale roughness (smooth roughness) as 1/30 of the median diameter $D_{p}$ of the undisturbed coarse mode particles (Marticorena and Bergametti, 1995). The moisture correction applies in cases when the soil moisture $w$ exceeds the threshold $w^{\prime}=0.0014 \cdot(\% \text { clay })^{2}+0.17 \cdot(\%$ clay $)$. The higher the clay content in the soil, the less likely dust production will occur under a given soil moisture content.

The sand transport model after White (1979) is used to obtain the streamwise horizontal saltation flux $Q_{\mathrm{MB} 95}\left(D_{p}\right) . g$ is the gravitational constant and $\rho_{\text {air }}$ the air density as before:

$$
\begin{aligned}
Q_{\mathrm{MB} 95}\left(D_{p}\right) & =C_{\mathrm{MB} 95} \cdot \frac{\rho_{\mathrm{air}}}{g} \cdot u_{*}^{3} \cdot\left(1+\frac{u_{* \mathrm{thr}}\left(D_{p}\right)}{u_{*}}\right) \\
& \cdot\left(1-\frac{u_{* \mathrm{thr}}^{2}\left(D_{p}\right)}{u_{*}^{2}}\right) .
\end{aligned}
$$

The correction factor $C_{\mathrm{MB} 95}$ (used to adjust the saltation flux according to experimental results) was originally set to 2.61 (Marticorena and Bergametti, 1995) but later revised to 1.0 (Marticorena et al., 1997) which is why we adopted $C_{\mathrm{MB} 95}=1.0$ in our box model set-up.

Alternatively, the sand transport formulations after Owen (1964) (OW64) and Lettau and Lettau (1978) (LL78) are applied for sensitivity test purposes.

OW64 considers the concentration and vertical distribution of saltating grains in the saltation layer above the ground, making use of the grain size terminal velocity $w_{\mathrm{s}} . w_{\mathrm{s}}$ is determined as a function of particle mass, diameter and the drag coefficient in consideration of different possible Reynolds regimes (Shao, 2008). The momentum flux is derived by relating upward and downward moving particles in the salta- tion layer. $C_{1}$ and $C_{2}$ (empirical constants to specify the ratio between $w_{\mathrm{s}}$ and $u_{*}$ ) have values of 0.25 and 0.33 , respectively (Sherman and Li, 2012):

$$
\begin{aligned}
\operatorname{Qow64}_{\text {ow }}\left(D_{p}\right) & =\frac{\rho_{\mathrm{air}}}{g} \cdot u_{*}^{3} \cdot\left(1-\frac{u_{* \mathrm{thr}}\left(D_{p}\right)^{2}}{u_{*}^{2}}\right) \\
& \cdot\left(C_{1}+C_{2} \cdot \frac{w_{\mathrm{s}}}{u_{*}}\right) .
\end{aligned}
$$

LL78 accounts for excess shear velocity relative to $u_{* \text { thr }}$. We use a factor of 6.7 for $C_{\mathrm{LL78}}$, and $D_{\text {ref }}$ is the reference grain size with a diameter of $250 \mu \mathrm{m}$ as used in wind tunnel experiments (Bagnold, 1941). $\rho_{p}$ is the soil particle density:

$$
Q_{\mathrm{LL} 78}\left(D_{p}\right)=C_{\mathrm{LL} 78} \cdot \sqrt{\frac{D_{p}}{D_{\text {ref }}}} \frac{\rho_{p}}{g} \cdot\left(u_{*}-u_{* \mathrm{thr}}\left(D_{p}\right)\right) \cdot u_{*}^{2} .
$$

The integrated horizontal flux $G$ relates $Q_{\text {MB95/OW64/LL78 }}$ to the relative surface area fraction $S_{\text {rel }}$, which is the percentage of soil grains with diameter $D_{p}$ relative to the total surface covered by soil particles. The minimally disturbed field soil sample size distribution is used in our case.

The integrated vertical mass flux $F_{\mathrm{MB} 95}\left(D_{p}\right)$ in the case of the MB95 scheme is obtained by means of an empirical approach which assumes a constant sandblasting (mass) efficiency $\alpha$ for each size bin. We use values between $1 \times 10^{-5}$ and $1 \times 10^{-7} \mathrm{~cm}^{-1}$ for the four corresponding parent soil types as suggested by Tegen et al. (2002). While this approach reflects aggregate disintegration to some extent as the emitted particle size spectra shift towards smaller particles compared to the horizontal mass flux, only mobilised particles (expressed in terms of $G$ ) will eventually be emitted. We try to minimise this problem by weighing each of the four bins according to its fraction in the fully disturbed field soil sample (see Table 1). The resulting sum of the four bins then determines the total $\alpha$.

\subsection{The Shao scheme}

The SH04 emission scheme is a more physical approach. Shao (2004) relate the binding energy of the dust particles to the threshold shear velocity. Over smooth surfaces, Shao and Lu (2000) derived $u_{* \text { dry }}$ by adjusting the empirical expression of Greeley and Iversen (1985):

$u_{* \text { dry }}\left(D_{p}\right)=\sqrt{A_{N} \cdot \frac{\rho_{p} \cdot g \cdot D_{p}}{\rho_{\text {air }}}+\frac{\Gamma}{\rho_{\text {air }} \cdot D_{p}}}$.

The interparticle cohesion force is considered as the combined effect of the van der Waals force and electrostatic force. It is assumed to be proportional to the soil particle size (Shao and $\mathrm{Lu}, 2000)$. The parameter $\Gamma$ accounts for the magnitude of the cohesive force and has values between $1.65 \times 10^{4}$ and $5.0 \times 10^{4} \mathrm{~kg} \mathrm{~s}^{-2}$. We use the smallest value which seems to fit best for the applied particle size range (Zhao et al., 
2006). The parameter $A_{N}$ is a dimensionless threshold friction velocity which is expressed as a function of the particle Reynolds number $R e_{t}$. The weak dependence upon $R e_{t}$ for dust particles led to a recommended factor of 0.0123 (Shao and $\mathrm{Lu}, 2000$ ).

For $R\left(z_{0}\right)$ in Eq. (1), a double drag partition scheme is proposed which treats bare and vegetated surfaces independently (Raupach, 1992; Raupach et al., 1993). In fact, it introduces a roughness density in terms of the frontal area covered by the non-erodible roughness elements present at the surface. As there is no vegetation present, we simplify the scheme such that it only depends on $\beta$ (ratio of the shear stress threshold of the bare erodible surface to the total shear stress threshold), $\sigma$ (ratio of the basal to frontal area of the roughness elements), $m$ (spatio-temporal variations of the underlying surface stress), and $\lambda\left(z_{0}\right)$ (roughness density of the non-erodible elements):

$R\left(z_{0}\right)=\sqrt{\frac{1}{1-m \cdot \sigma \cdot \lambda\left(z_{0}\right)}} \cdot \sqrt{\frac{1}{1+m \cdot \beta \cdot \lambda\left(z_{0}\right)}}$.

Although a wide range of $\beta$ values has been measured depending on surface type (King et al., 2005), we adopt values from Raupach et al. (1993) for $\beta$ as well as $\sigma$ and $m$ ( $\beta=90$; $\sigma=1 ; m=0.5$ ). For $\lambda\left(z_{0}\right)$, we take the values (based on field measurements; Marticorena et al., 2006) given in Table 2 in Darmenova et al. (2009) according to our observed $z_{0}$ values at each field site. For $H(w)$, a straightforward formulation based on wind tunnel experiments (Shao et al., 1996) as proposed by Zhao et al. (2006) is applied in the SH04 scheme as one choice:

$H(w)= \begin{cases}e^{22.7 \cdot w} & w<0.03 \\ e^{95.3 \cdot w-2.03} & w>0.03\end{cases}$

The sand transport formulation based on the OW64 model (Owen, 1964) is used in the SH04 horizontal flux parameterisation. The dimensionless constant $C_{\mathrm{SH} 04}$ can vary between 1.8 and 3.1 and is set to 2.45 in our experiments (Kawamura, 1964; Shao, 2008):

$Q_{\mathrm{SH} 04}\left(D_{p}\right)=C_{\mathrm{SH} 04} \cdot \frac{\rho_{\mathrm{air}} \cdot u_{*}^{3}}{g} \cdot\left(1-\frac{u_{* \mathrm{thr}}\left(D_{p}\right)}{u_{*}}\right)$.

The integrated horizontal flux $G$ relates $Q_{\mathrm{SH} 04}$ to the relative surface area fraction of each bin (denoted here as $p_{A}\left(D_{p}\right)$ instead of $\left.S_{\text {rel }}\right)$. As for MB95, we use the size distribution of the minimally disturbed soil sample.

For the integrated vertical mass flux, Shao (2001) proposed a scheme that accounts for saltation bombardment and aggregate disintegration. We use the simplified version introduced by Shao (2004). The size range of particles emitted by saltation bombardment differs from that of saltating particles (those in the horizontal saltation flux). While SH04 specifies a certain size range, we keep the original size range of the four parent soil types for saltating as well as sandblasted particles. However, we account for the changing size range by applying the prescribed (i.e. observed) minimally $\left(p_{\mathrm{m}}\left(D_{p_{\mathrm{m}}}\right)\right)$ and fully disturbed $\left(p_{\mathrm{f}}\left(D_{p_{\mathrm{f}}}\right)\right)$ volume size distributions. It is assumed that the undisturbed soil sample represents the saltating particles, while the fully disturbed soil sample represents the smaller particles which control the vertical emission dust mass flux (and hence account for aggregate disintegration). If strong erosion occurs, the scheme acts to shift the soil particle size distribution towards the fully disturbed sample. Furthermore, the ratio of auto-abrasion is parameterised by the free-dust-to-aggregated-dust mass ratio $\sigma_{p}=p_{\mathrm{m}}\left(D_{p_{\mathrm{m}}}\right) / p_{\mathrm{f}}\left(D_{p_{\mathrm{f}}}\right)$. The corresponding vertical flux formulation is the following:

$$
\begin{gathered}
F_{\mathrm{SH} 04}\left(D_{p_{\mathrm{m}}}, D_{p_{\mathrm{f}}}\right)=c_{\gamma} \cdot \eta_{\mathrm{f}}\left(D_{p_{\mathrm{f}}}\right) \cdot\left((1-\gamma)+\left(\gamma \cdot \sigma_{p}\right)\right) \\
\cdot\left(1+\sigma_{m}\right) \cdot \frac{Q_{\mathrm{SH} 04}\left(D_{p_{\mathrm{m}}}\right) \cdot g}{u_{*}^{2}} .
\end{gathered}
$$

Here, $\gamma$ is specified as $\gamma=e^{-\left(u_{*}-u_{* \mathrm{hr}}\right)^{3}}$, while $\eta_{\mathrm{f}}\left(D_{p_{\mathrm{f}}}\right)$ refers to the mass fraction of the dust particles having diameters less than $20 \mu \mathrm{m}$. We assume the mass fractions of the fully disturbed soil sample to be representative of that (it contains only clay- and silt-sized particles in most cases, as shown in Table 1). The parameter $\sigma_{m}$ depends on $u_{*}$, the plastic pressure $p$ of the soil surface and the bulk soil density $\rho_{\mathrm{b}}$. Together with $c_{\gamma}$, the latter two values are taken from Shao (2004) assuming sandy loamy soil conditions on average at the field site. The flux of the individual bins is finally integrated over the entire particle size range.

\subsection{The Alfaro scheme}

Similar to Shao (2004), Alfaro and Gomes (2001) offer a more sophisticated scheme for the conversion of the horizontal flux into the vertical mass flux compared to MB95. However, AG01 requires the calculation of the saltation mass flux as a prior condition. While AG01 has been combined with the MB95 horizontal flux scheme before (Menut et al., 2005; Darmenova et al., 2009), in our experiments we use the SH04 horizontal flux as input parameter. It enables us to evaluate the performance of two complex vertical flux schemes which both attempt to describe the physical processes involved. Instead of four size bins, we use a discretised full-resolution soil size distribution in order to calculate the $\mathrm{SH} 04$ horizontal flux as it is required for the AG01 scheme. The size distribution is assumed to follow a multimodal lognormal shape with geometric mean diameters identical to the parent soil size bins $(2,15,160,710 \mu \mathrm{m})$ (Menut et al., 2005). Accordingly, the relative surface area fraction $S_{\text {rel }}$ is recalculated for the discretised particle size spectra, with $D_{p_{k}}$ referring to the diameter of the discretised full-resolution soil size distribution in the range of $D_{p_{\min }}$ and $D_{p_{\max }}$ with number $N_{\text {class. }}$.

The AG01 scheme takes the individual kinetic energy $E_{\text {kin }}$ of saltating soil grains required to separate dust particles en- 
tirely from each other by overcoming the interparticle cohesion forces into account. The dust emitted by sandblasting is characterised by three modes $i$ which are considered to be independent of the soil grain type (Alfaro et al., 1998; Menut et al., 2005). As soil aggregate size or model wind speed increases, first a coarse mode particle with the lowest cohesion energy $e_{i}$ becomes released by $E_{\text {kin }}$, followed by intermediate and fine mode particles. The vertical dust flux in this case becomes

$$
\begin{aligned}
F_{\mathrm{AG} 01}\left(D_{p_{i}}, D_{m_{k}}\right) & =\sum_{k=1}^{N_{\text {class }}} \frac{\pi}{6} \cdot \rho \cdot \beta_{\mathrm{AG} 01} \\
& \cdot \frac{p_{i}\left(D_{p_{k}}\right) \cdot D_{m_{i}}^{3}}{e_{i}} \mathrm{~d} G\left(D_{p_{k}}\right) .
\end{aligned}
$$

Here, $D_{m_{i}}$ is the mean mass diameter of the three soil grain modes $(1.5,6.7,14.2 \mu \mathrm{m}), \beta_{\mathrm{AG} 01}$ is an empirically derived parameter $\left(163 \mathrm{~m} \mathrm{~s}^{-2}\right)$, and $p_{i}\left(D_{p_{k}}\right)$ are the fractions of $E_{\mathrm{kin}}$ required for the release of the dust particles in the respective mode (Alfaro et al., 1997). Note that the AG01 scheme does not provide a size-resolved dust emission flux as the discretised particle size spectrum in which the interparticle energy exchange forces act comprises a distinctively different size range than that of the emission flux. One could redistribute the accumulated dust over the four parent soil classes according to the observed disturbed size sample, but this would not be an actual prediction of this particular emission scheme. As noted by Darmenova et al. (2009), it is unlikely that interparticle cohesion can ever be predicted with the desired accuracy in order to resolve this problem in a satisfactory manner.

\subsection{Box model experiments}

To test the box model, we run the model with observational data as well as academic data (full range of possible shear velocities). This enables us to (1) estimate the sensitivity of the model to simulate dust emission, and (2) attribute the discrepancies to specific components of the emission schemes, or the choice of the emission scheme itself. We also test the critical parameter $\alpha$ as a function of $u_{*}$. The set of experiments used in these exercises is schematically shown in Table 2. Each experiment uses a specific model set-up based on the schemes introduced in Sect. 2: the sand transport model, the saltation flux and the vertical dust flux scheme.

For the first runs, we only use experiments $1 \mathrm{a}, 4 \mathrm{a}$ and 5a, i.e. all correction schemes switched on, using the MB95, SH04 and AG01 schemes for the vertical emission flux. We focus on the most emissive period during the 2011 campaign, selecting a 30 day interval with three major dust events (17 September-17 October 2011). The field campaign begins with the end of the dry season in March/April. Conditions become increasingly dry, with average daytime maximum temperatures typically reaching $>35^{\circ} \mathrm{C}$. Note that the rate of decrease in soil moisture varies between each individual field site and throughout time. Higher surface temperatures are
Table 2. Individual model set-ups (1-5) and the conducted experiments (a-d). The sand transport models (STM) used for the two principal horizontal flux (HFlux) models (MB95, SH04) and the selected vertical flux (VFlux) schemes with the number of the corresponding set-up are given. The lower-case letters refer to the sensitivity experiments with the correction schemes.

\begin{tabular}{cccccc}
\hline Exp & HFlux & STM & VFlux & dragC & moistC \\
\hline 1 & MB95 & MB95 & MB95 & & \\
2 & MB95 & OW64 & MB95 & & \\
3 & MB95 & LL78 & MB95 & & \\
4 & SH04 & SH04 & SH04 & & \\
5 & SH04 & SH04 & AG01 & & \\
\hline a & $*$ & $*$ & $*$ & ON & ON \\
b & $*$ & $*$ & $*$ & ON & OFF \\
c & $*$ & $*$ & $*$ & OFF & ON \\
d & $*$ & $*$ & $*$ & OFF & OFF \\
\hline
\end{tabular}

* Experiments are carried out for each model set-up (1-5).

accompanied by increasing boundary layer turbulence. Both the increased availability of momentum and deflatable dust explain the more active late season during the first part of the DO4Models campaign. The dust emission season ended with the first rains in mid-October.

For the second and third set of model runs, the box model is configured to represent a single atmospheric model grid cell. We use the temporally resolved average roughness, soil moisture, and particle size distribution to drive the model. For each experiment set-up, the model is manipulated with (a) all corrections schemes switched on, (b) the soil moisture correction scheme (Eq. 2) switched off, (c) the drag partition correction scheme (Eq. 3) switched off, and (d) both correction schemes switched off.

Darmenova et al. (2009) pointed out that the soil moisture correction after Zhao et al. (2006) (see Eq. 9) might be excessively sensitive to changes in the soil moisture content. This will be tested using the MB95 formulation given in Eq. (3). The same will be done with Eq. (2) for roughness. In addition, the corresponding sensitivity of the simulated fluxes is discussed in the context of the observed fluxes.

\section{Results and discussion}

We start with an overview of observed dust emissions from the field site and compare them with the box model results in Sect. 4.1. We then test the emission schemes over a range of shear velocities and quantify the differences with observations (Sect. 4.2). This is followed by an exploration of separate box model components (soil moisture and drag partition correction scheme; sand transport formulation) in an attempt to diagnose model-observation differences in emission (Sect. 4.3). The examination of the box model results is accompanied by a discussion of the errors and uncertainties 
involved. The applicability of the existing emission schemes is discussed on the basis of our model results and implications for regional and global dust modelling are highlighted in Sect. 4.4.

\subsection{Model performance during the field campaign}

During our chosen period of highest emission activity, three major dust events were recorded: 25 September (DOY 268), 2 October (DOY 275), and 3 October (DOY 276), as evident in the observational data at $2 \mathrm{~min}$ temporal resolution (Figs. 2-4). Peak wind speeds at $6 \mathrm{~m}$ height reached up to $18 \mathrm{~m} \mathrm{~s}^{-1}$. Corresponding maximum $u_{*}$ values as high as $0.9 \mathrm{~m} \mathrm{~s}^{-1}$ were observed (with regard to $\Delta t=2 \mathrm{~min}$ ). Two smaller events were recorded on 17 September (DOY 260) and on 6 October 2011 (DOY 279), though $u_{*}$ did not reach a threshold of $0.4 \mathrm{~m} \mathrm{~s}^{-1}$ at all sites. Simultaneously during these wind events, decreasing Ångström exponents obtained from CIMEL data indicated dust loadings rather than biomass burning as the dominant aerosol type. The comparison between observed and simulated horizontal and vertical fluxes is shown in Figs. 2, 3, and 4, corresponding to the baseline Exps. 1a (MB95), 4a (SH04) and 5a (AG01), respectively. In order to provide a representative view of dust emissions, the most emissive site I4 (red border), the least emissive site L5 (blue border), and three average sites, B3, D10, and J11 were evaluated to provide perspectives on the role of surface type and emissivity.

Site I4 shows a pronounced flux signal during the three major dust events (Fig. 2c). Another small event was recorded on 6 October 2011 (DOY 279). The temporal agreement between the modelled fluxes and the observed peak shear velocities over the 17 September-17 October period (2 min temporal resolution) is highest at site I4, particularly for MB95. However, the modelled horizontal flux - associated with the saltation flux - overestimates the observed horizontal flux by 3 to 4 orders of magnitude. This discrepancy exists regardless of the strength of the dust event. The modelled vertical emission flux - associated with the sandblasting process - overestimates the observed vertical flux approximately by an order of magnitude. While the model performance is ultimately measured in terms of vertical emission flux (arguably with a much smaller model vs. observation mismatch), the sandblasting efficiency $\alpha$ differs by 2 to 3 orders of magnitude between model and observation (see Fig. 6 and the discussion in Sect. 4.3.1).

At sites B3 and D10, only one major saltation event was recorded (Fig. 2a, g). Likewise, vertical dust flux was calculated from concentration measurements for only one time interval at B3 (Fig. 2b). D10 did not emit at all, despite favourable observed soil moisture conditions (Fig. 2h). Due to the low soil moisture at both sites (a considerable drop for B3 after DOY 270), the emission threshold in the MB95 model is frequently exceeded, leading to substantially more frequent dust emissions. As at site I4, the modelled saltation flux during the event on 2 October (DOY 275) at sites B3 and D10 is strongly overestimated by up to 4 orders of magnitude. The vertical dust flux at B3 during the same event is overestimated by 1 to 2 orders of magnitude. A few Sensit hits were recorded (expressed in terms of $Q_{\mathrm{OBS}}$ in Fig. 2e) at L5, associated with a rare number of events where vertical dust emission flux was measured (Fig. 2f). Both observed fluxes and the low shear velocity at L5 are a result of very smooth surface conditions in combination with very wet subsurface conditions. Equally wet soil conditions at J11 lead to the suppression of dust emissions in the model (Fig. 2i, j) altogether. As a consequence, the model does not simulate dust emission during the event on 25 September (DOY 268).

There are more frequent dust emissions with higher concentrations simulated with SH04 compared with MB95 (Fig. 3). The saltation flux is also strongly overestimated by approx. 4 orders of magnitude, whereas the vertical dust emission flux is overestimated by 1 to 2 orders of magnitude. Sites B3 and D10 showcase the effect low soil moisture conditions will have upon the modelled emission fluxes (Fig. 3a, b, g, h). Unambiguously, the emission threshold is exceeded far more often in the model at sites I4 and D10 (Fig. 3c, d, g, h). Site D10 reveals a potential advantage of the more complex SH04 scheme: the modelled saltation flux does not necessarily result in an equally overestimated vertical dust mass flux due to the variable sandblasting efficiency. In contrast, the saltation flux is more strongly overestimated in SH04 compared to MB95. Fluxes with SH04 at site L5 are similar to fluxes simulated with MB95 (Fig. 3e, f). The temporal agreement between observed and modelled fluxes at site $\mathrm{J} 11$ is better with SH04 than with MB95 (Fig. 3i, j).

There is close agreement in the case of the saltation fluxes between AG01 and SH04. This is to be expected given that both experiments differ from one another only in the way the size bins are partitioned (see Sect. 3.3). At the same time, the good agreement between both saltation flux estimates is indicative of a limited impact of the size bin resolution on the resulting dust flux estimate. The modelled vertical fluxes in both schemes are different to those in MB95, LL78, and OW64 in two ways though: (1) vertical fluxes are more frequent due to substantially higher saltation fluxes in the first place, and (2) the magnitude of the vertical fluxes with AG01 is on average the lowest of all schemes used in our experiments. The observed dust emission flux is overestimated by less than an order of magnitude in the model with AG01. While modelled fluxes at B3, I4 and D10 occur much more frequently than observed fluxes (Fig. 4b, d, h), L5 and J11 (Fig. 4f, j) agree very well in that regard.

In essence, both the frequency and strength of the dust emission flux are poorly reproduced in the three emission schemes. The emission threshold is least underestimated in MB95. The vertical emission flux is least overestimated in AG01. 

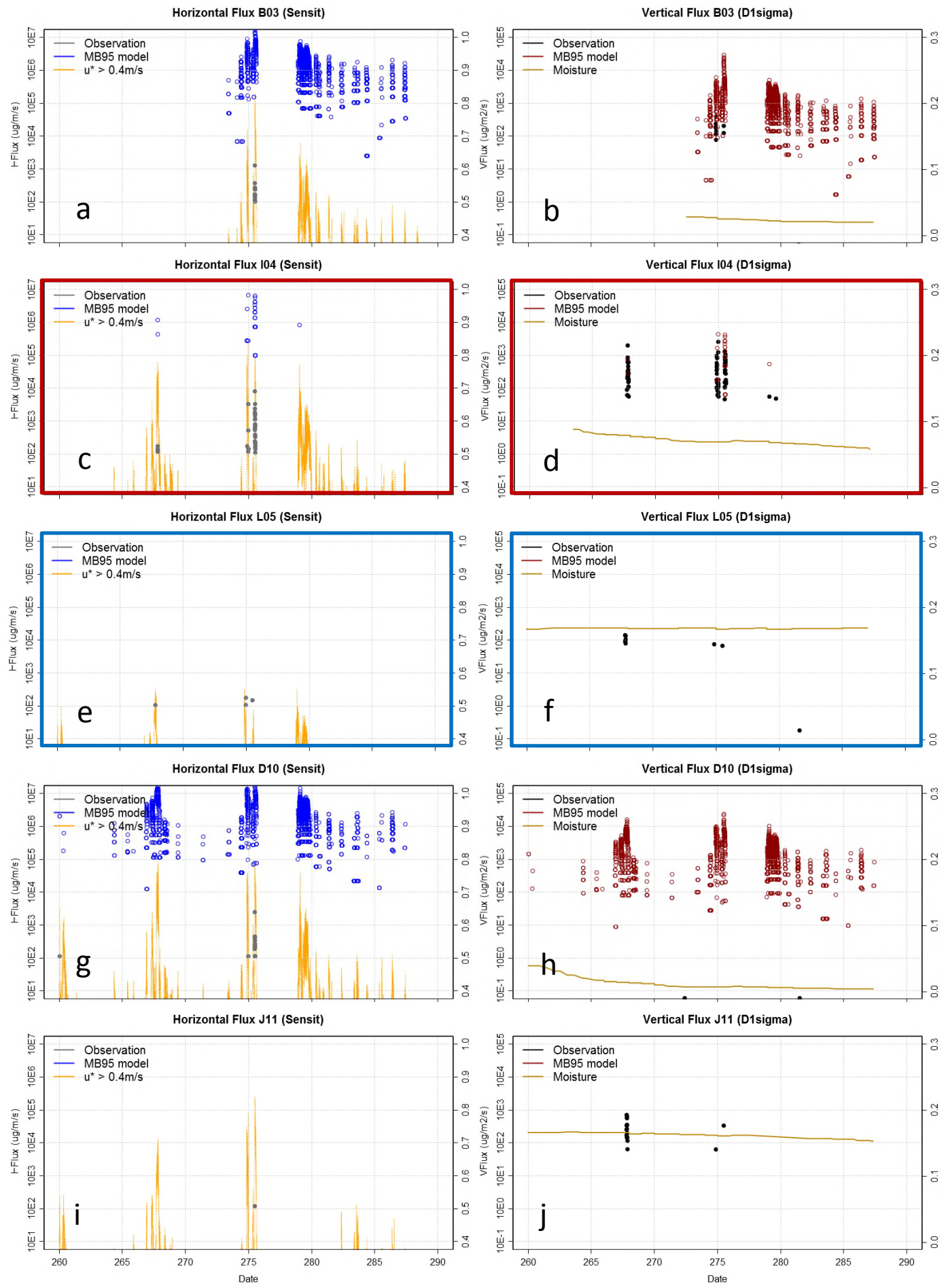

Figure 2. Horizontal and vertical flux for Exp. 1a (MB95 scheme) at five field sites: B3 (a, b), I4 (c, d), L5 (e, f), D10 (g, h), and J11 (i, j). The observed (modelled) saltation and vertical fluxes are shown in grey (blue) and black (dark red) dots. The period between DOY 260 (17 September) and DOY 290 (17 October 2011) is shown. The box model is driven with observed $u_{*}$ values. On the left-hand side, the shear velocity is shown (orange; values on the right ordinate). On the right-hand side, the soil moisture content below $0.3 \mathrm{~m}^{3} \mathrm{~m}^{-3}$ is shown (dark yellow; values on the right ordinate). Site I4 is referred to as a dusty site (c, d). Site L5 emitted least throughout the 2011 campaign (e, f). I4 and L5 are marked with red and blue borders throughout the manuscript. 

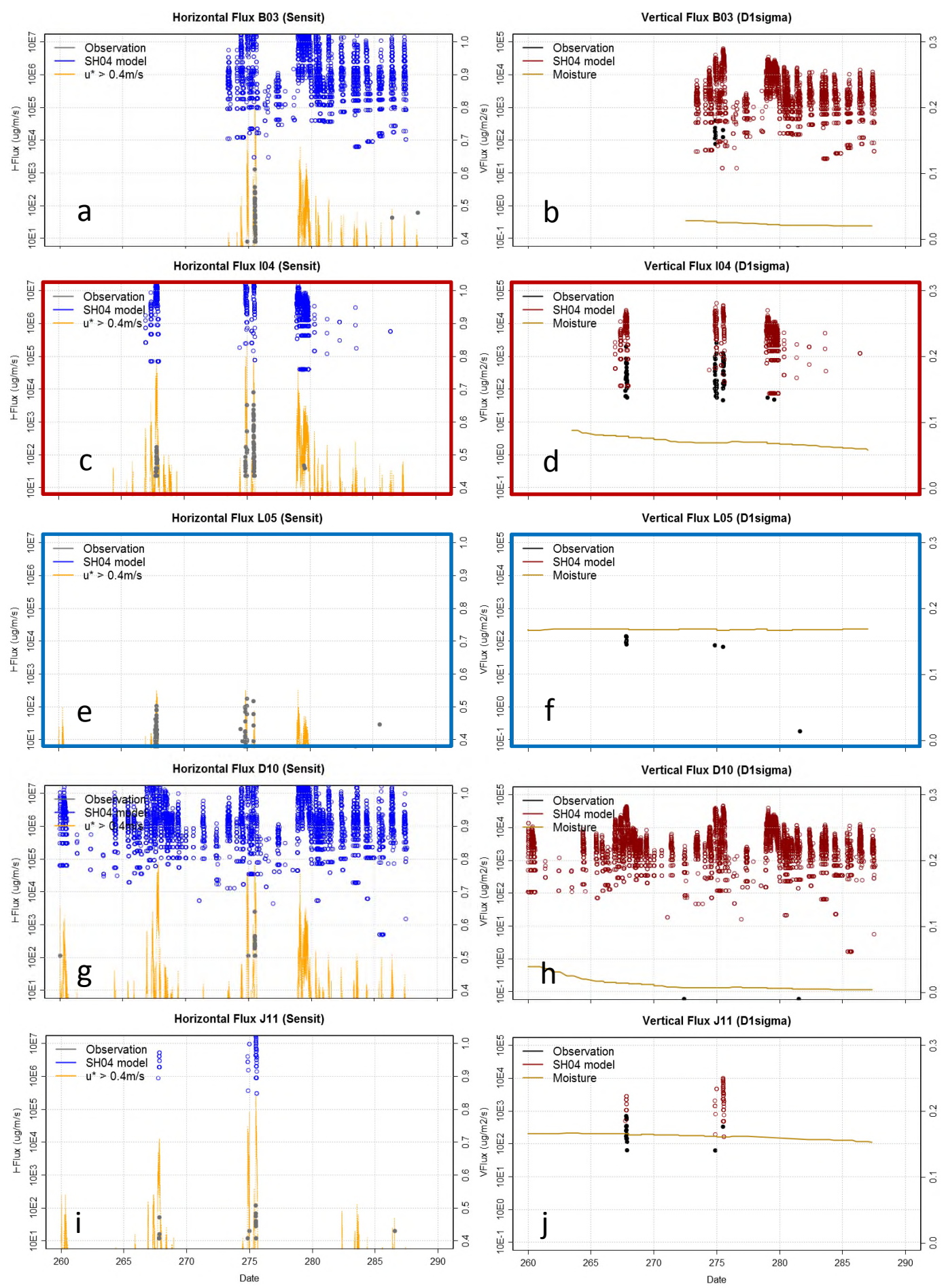

Figure 3. Same as Fig. 2 but for Exp. 4a (SH04 scheme). 

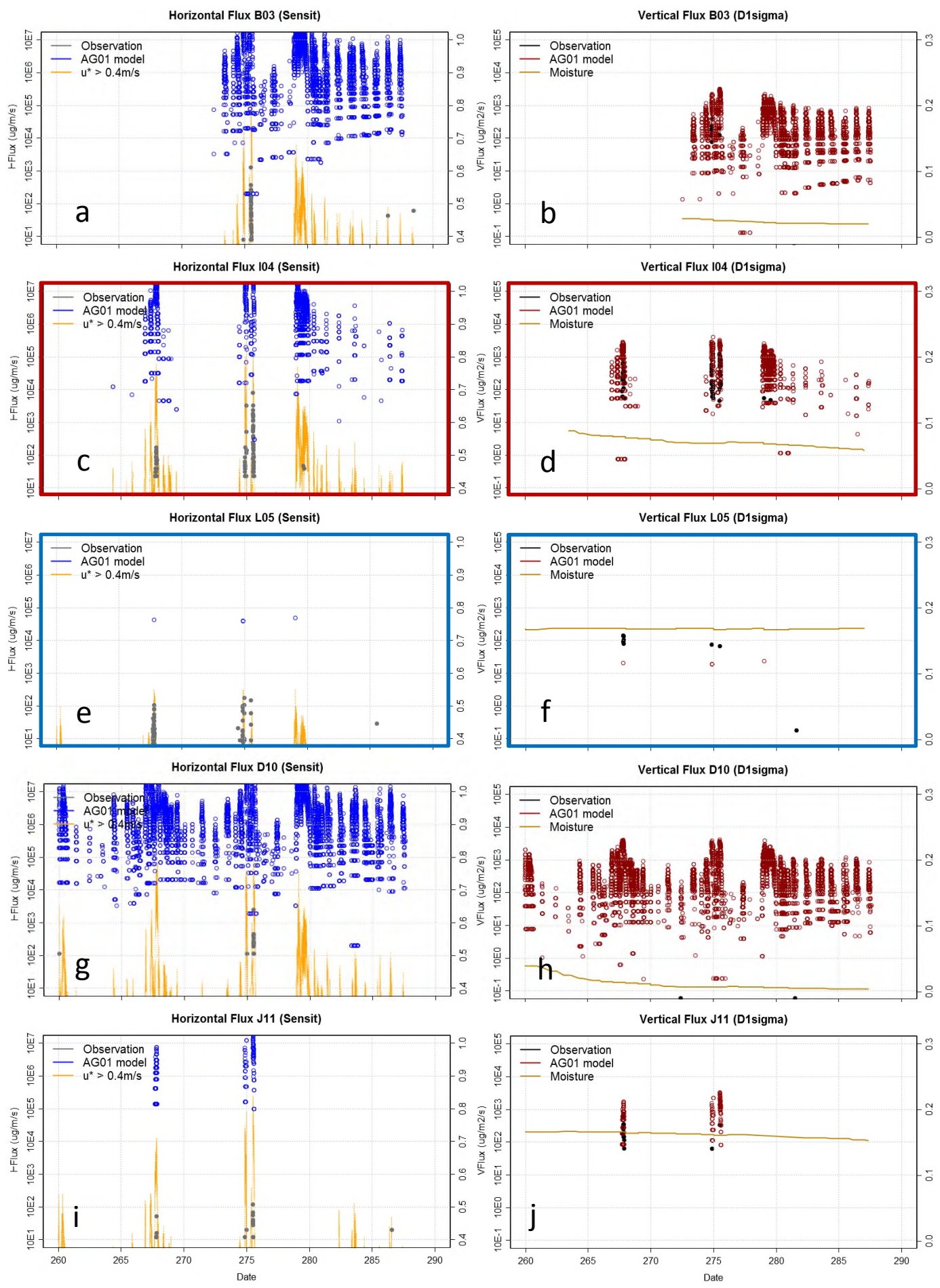

Figure 4. Same as Fig. 2 but for Exp. 5a (AG01 scheme). 


\subsection{Examination of dust transport/emission schemes}

Before we elaborate on the potential causes of this mismatch between observed and modelled fluxes as well as for the substantial differences between the emission schemes, we explore the impact of the emission and sand transport schemes upon the simulated saltation and vertical flux in a wider context. We focus on Exps. 1a-5a and Exps. 1d-5d as shown in Fig. 5a, b and c, d, respectively. The simulated horizontal (Fig. 5a, c) and vertical fluxes (Fig. 5b, d) represent the sum of the individual fluxes for each parent soil type. Note that the AG01 scheme (Exp. 5a) uses a sub-bin size distribution of which only the total sum is shown, whereas the clay, silt, fine/medium and coarse sand fractions are shown individually (thin lines) in addition to the sum of all four bins (bold lines) for the MB95, LL78, OW64, and SH04 schemes (Exp. 1a-4a). Note also that the emission threshold is exceeded only for the silt, fine/medium and coarse sand fractions $\left(u_{* \text { thr }}\right.$ (clay) $\left.>1.4 \mathrm{~m} \mathrm{~s}^{-1}\right)$. Box model fluxes are computed using observed data as before, averaged over the entire time period of the field campaign and all grid points (see Table 1).

Model Exps. 1a-5a (Fig. 5a and b) reconfirm the results of the preceding section. The saltation flux in model schemes is overestimated by 3 to 4 orders of magnitude, whereas the simulated vertical flux is overestimated by 1 to 2 orders of magnitude in all schemes, with AG01 and OW64 showing the smallest mismatch regarding the vertical flux (cyan line in Fig. 5b). SH04 has a $0.2 \mathrm{~m} \mathrm{~s}^{-1}$ lower threshold velocity than AG01 and MB95. As our observed $u_{*}$ never exceeds $0.85 \mathrm{~m} \mathrm{~s}^{-1}$, we can only speculate whether we would have observed disproportionally increasing saltation flux rates with higher surface shear stress.

Model Exps. 1d-5d (Fig. 5c and d) reveal a surprisingly close range of threshold shear values for all schemes. They start to emit at $u_{*} \sim 0.2 \mathrm{~m} \mathrm{~s}^{-1}$ with no exception. While the simulated emission fluxes are still too high, the underlying sand transport concept is robust in all schemes with respect to the emission threshold. Beyond the minimum erosion threshold, soil moisture content and surface roughness fundamentally control the frequency of occurrence of dust emissions.

Summarising the key aspects of the two sections, we find that the model (1) strongly overestimates the saltation flux and moderately overestimates the vertical emission flux, and (2) tends to be very sensitive to changes in moisture and roughness, leading to inconsistent or inaccurate emission thresholds for individual field sites. The general discrepancy between model results and observations indicates that the emission schemes have problems in representing key physical processes over crusted soil surfaces properly.

\subsection{Potential reasons for the model discrepancies}

In this section, we aim to understand the causes of the box model-observation discrepancies. Specifically, we aim to identify the parameters that contribute the largest to the model-observation differences. Considering the empirical basis of the emission schemes, it is worth noting that MB95 (mainly based on the formulation after Iversen and White, 1982) as well as SH04 (based on the formulation after Greeley and Iversen, 1985) rely on the theoretical concept of equilibrium between forces acting on a spherical loose particle at rest and under the influence of an air stream. As cautioned by Marticorena and Bergametti (1995), this theoretical assumption is bound to break down if loose particles are hidden under a resistant crust. The same is true for the concept of equilibrium between gravitational and interparticle cohesion forces which is the basis of $\mathrm{SH} 04$ as it was developed in Shao and Lu (2000). While SH04 allows adjustment to the magnitude of the cohesive force (parameter $\Gamma$ ), MB95 is limited in this regard. Deficiencies arising from the MB95 saltation flux formulation are directly passed to the vertical flux estimate. In turn, the explicit formulation of $\alpha$ in SH04 could potentially reduce intrinsic weaknesses of the saltation flux formulation.

\subsubsection{Problems in the simulated fluxes}

Given that the model overestimates the saltation flux much more than the vertical flux - irrespective of the emission scheme - evaluation of the vertical-to-horizontal flux ratio $\alpha$ is necessary. In Fig. 6, the discrepancy between the observed and modelled ratio is represented by the distance between the filled coloured dots $\left(\alpha_{\mathrm{OBS}}\right)$ and the open coloured dots $\left(\alpha_{\text {MB95}}\right.$; Exp. 1a) or triangles $\left(\alpha_{\mathrm{SH} 04}\right.$; Exp. 4a), respectively. The temporal resolution between two flux measurements in our data is $2 \mathrm{~min}$, which requires coincident observations of $F_{\mathrm{OBS}}>0.0 \mathrm{mg} \mathrm{m}^{-1} \mathrm{~s}^{-1}$ and $Q_{\mathrm{OBS}}>0.0 \mu \mathrm{g} \mathrm{m}^{-2} \mathrm{~s}^{-1}$ to determine $\alpha_{\mathrm{OBS}}$. This condition is only met at site I4 for two dozens of 2 min measurement intervals, mainly referring to DOY 275 (Fig. 6c). B3 provides sparse additional values (Fig. 6a). L5 (Fig. 6g) is discussed later in this section. The remaining sites are plotted in order to show the variability of the modelled $\alpha_{(\mathrm{MB} 95 / \mathrm{SH} 04)}$.

With the simple MB95 scheme in place, $\alpha$ is strictly constant at each site. The more complex SH04 scheme allows for a varying $\alpha$ in response to changes in soil composition, surface roughness and soil moisture content. The observed changes in $z_{0}$ and $w$ over the 3 month field interval have a profound impact on the modelled $\alpha$, as can be seen in Fig. 6 a (B3) and i (D10). The SH04 ratio varies by up to 1 order of magnitude (as a function of soil moisture which varies over time as reflected in the associated 10 day time interval) and can either be smaller or larger than the constant MB95 ratio. Despite the model variability, what is really striking is the mismatch of 2 to 4 orders of magnitude between observed and modelled $\alpha$ at I4 (Fig. 6c) as initially outlined in Sect. 4.1. The weak observed saltation flux causes $\alpha$ to be unprecedentedly high. The majority of the $\alpha$ values lie between $1 \times 10^{-1}$ and $1 \times 10^{-3} \mathrm{~cm}^{-1}$. 


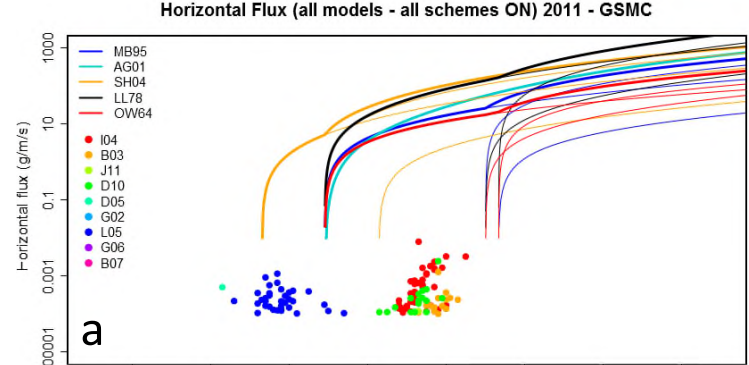

Horizontal Flux (all models - moist \& drag corr OFF) 2011 - GSMC

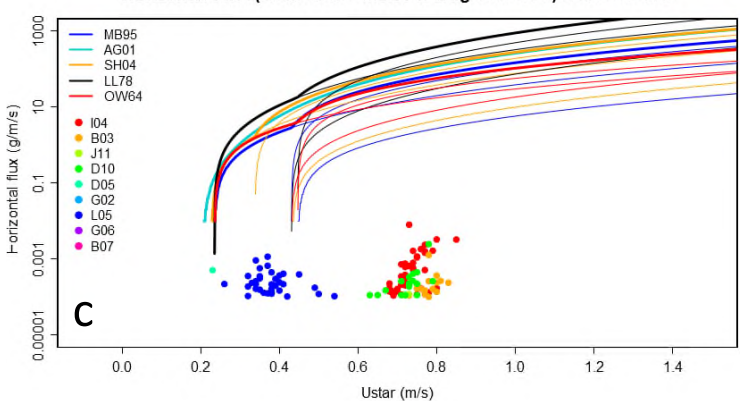

Vertical Flux (all models) - 1sigma Dconc (all schemes ON) 2011 - GSMC

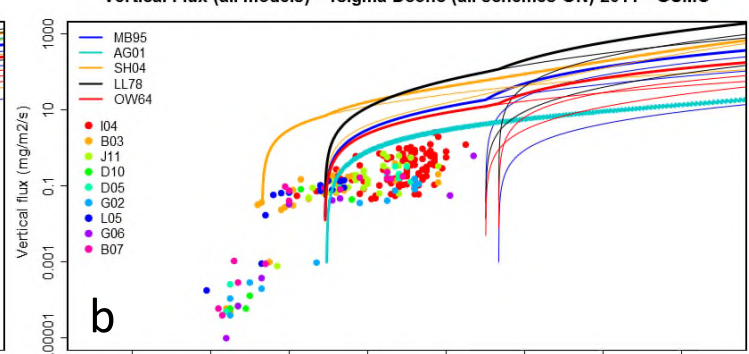

Vertical Flux (all models) - 1 sigma Dconc (moist \& drag corr OFF) 2011 - GSMC

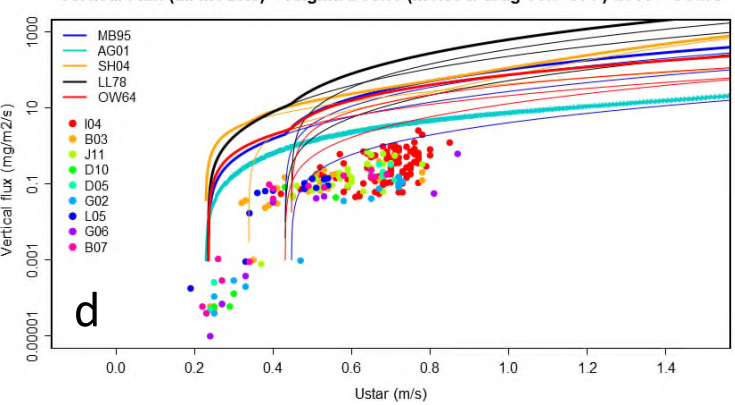

Figure 5. Horizontal and vertical emission fluxes for Exps. 1a-5a (a, b) and Exps. 1d-5d (c, d). Bold lines are the sum of the flux over all four size bins. Thin lines are individual model particle size categories (fine/medium sand is emitted first). Coloured circles are the field observations.

On the basis of the surface conditions at our most emissive site I4, which features a thin crust with open cells filled with very fine deflatable particles, we hypothesise that saltating particles are likely to be trapped by the salt-containing fluff in these open cells which then absorbs the saltation momentum. Under the assumption that I4 is not a source of larger saltating particles itself, it represents a net sink for creeping and saltating particles, which leads to a cessation in the saltation flux. While the horizontal flux ceases, the comparably high shear stress maintains the vertical flux of smaller particles, though at a less efficient rate. Hence, direct entrainment (production of vertical flux without saltating particles) has a larger share in the total emission flux. Whether the shape of the cells or the chemical properties of the fluff material are the major cause of I4 being a saltation sink remains to be explored. In contrast to I4, sustained particle motion (hitting the Sensit counter persistently) was observed at site L5 during the wind events, without ever recording actual vertical emission of finer particles. Wet sub-surface conditions led to the development of a fresh but very smooth and resistant crust at L5. Counter-intuitively, the smooth surface allowed coarser particles (advected from contiguous pan surfaces with broken crusts) to move easily. Presumably, the observed saltation flux at L5 is a result of the very exceptional surface conditions due to L5's situation on the grid.

Neither the shape of a partly crusted and rippled surface nor the crust itself is represented in our schemes, and this is likely the main cause of the large gap between observed and modelled fluxes. While the theoretical basis of the sand transport and dust emission schemes is well established and often successfully reproduced (e.g. Shao, 2001, 2008), the observed crust puts a considerable limit on their applicability in our case. One might argue that it is of lesser relevance to reproduce the saltation flux quantitatively correctly in the model as long as the vertical emission flux is correctly balanced, but this inevitably implies the acceptance of fundamental errors in the parameterisation of the nature of the dust emission process. While the initial emission threshold is very sensitive to $z_{0}, w$, and particle size, these factors become less important at higher wind speeds, as the sand transport scheme controls the bulk of the vertical dust emission flux.

This study is not the first to report on diverging $\alpha$ values. Based on measurements with a sand particle counter (saltation flux) and an optical particle counter, Shao et al. (2011a) obtained similar values to ours for $\alpha$ over bare soil during the Japan Australia Dust Experiment (JADE) (Ishizuka et al., $2008,2014)$. On the basis of their findings, they proposed that convective turbulent dust emission might play an important role. We concur with this proposition as we have indeed been observing frequent dust devils over the pan, indicative of large eddies generated by localised momentum fluxes to the surface which intermittently receives a surge of strong shear stress leading to direct dust entrainment (Klose and Shao, 2013). Ishizuka et al. (2014) also highlight the size dependency of the emission flux, as evident in their field data. Other studies matched empirical expectations quite well. For example, Gillette (1978) using test soils, Nickling and Gillies (1993) in Mali, Gillette et al. (1997) and Nickling et al. (2000) at Owens Lake, USA, Nickling et al. (1999) in Queensland, Australia, Rajot et al. (2003) in Niger, or Gomes 

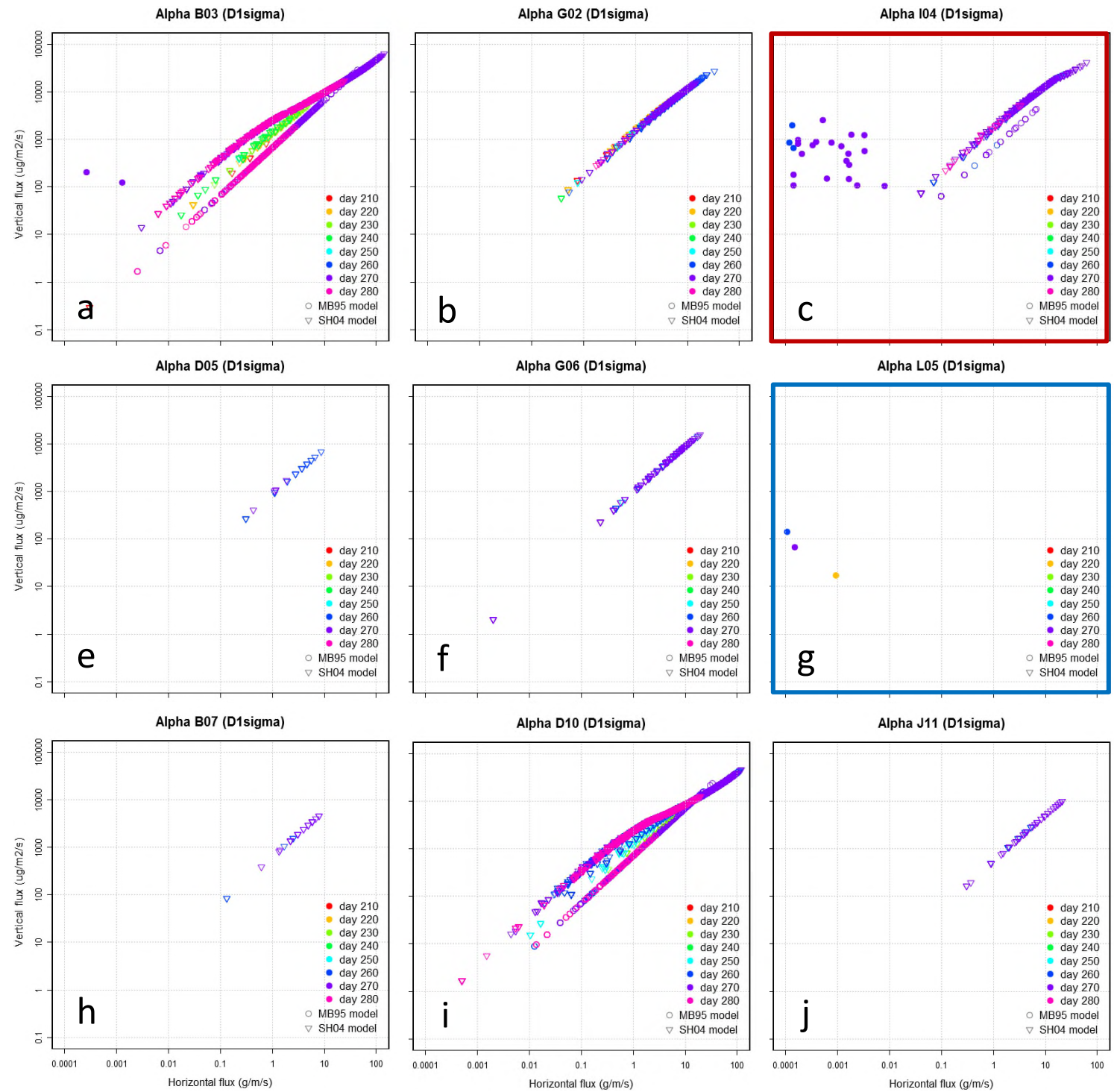

Figure 6. The temporal evolution of the simulated vertical-to-horizontal flux ratio $\alpha$ for Exp. 1a (open circles) and 4a (open triangles) is shown in comparison to the observed values (closed circles). The colour refers to 10 day time intervals during the field season, with the start DOY given for each period. Nine out of 11 field sites are shown. In cases of $F_{\text {OBS }}$ without simultaneous $Q_{\text {OBS }}, \alpha$ is zero. Note that there are situations in which vertical emission flux was measured without saltating particles.

et al. (2003) in Spain, all found $\alpha$ values in good agreement with theory. These studies have in common that wind tunnels were used to determine the fluxes experimentally, a fact that might well be key to understanding the difference between their reported results and our field data.

\subsubsection{Problems in the correction schemes}

The remaining variability of the calculated dust fluxes is determined by the correction schemes for surface roughness and soil moisture content - both known to have a large impact on modelled mineral dust emission fluxes (Menut et al., 2013). The full range of sensitivities for the baseline ex- periments $(1 \mathrm{a}, 4 \mathrm{a})$ is shown in Fig. 7. For $z_{0}$, the observed range is $0.001 \mathrm{~cm}<z_{0}<1.0 \mathrm{~cm}$. The minimum and maximum value for $w$ has also been chosen according to the respective range of observed values: $0.01<w<0.16 \mathrm{~m}^{3} \mathrm{~m}^{-3}$. It is expressed in equivalent terms of percent water per soil volume. For Exp. 1a, the range of $u_{* \text { thr varies between } 0.25}$ and $0.8 \mathrm{~m} \mathrm{~s}^{-1}$. The threshold shear velocity is equally sensitive to both, $z_{0}$ and $w$, yielding a corresponding inhibition of the simulated fluxes. The higher the $u_{* \text { thr }}$, the lower the simulated fluxes once the threshold is exceeded. Exp. 4a is similarly sensitive to $z_{0}$. In turn, for increasing $w$, it tends to increase the emission threshold exponentially rather than linearly. As noted in Sect. 3.2, it is the scheme after Fécan et al. 
(1999) as used in MB95. The scheme proposed by Zhao et al. (2006) (Eq. 9) would span twice the range of potential $u_{* \text { thr }}$ values, which cannot be reconciled with the observed sensitivity (not shown).

In Fig. 7, the observed fluxes are divided into the same sub-categories. The results show that sites with the highest observed saltation fluxes have a very limited range of $z_{0}(0.1-$ $1 \mathrm{~cm})$. Likewise, the range of $w$ is confined to lower values $\left(<0.11 \mathrm{~m}^{3} \mathrm{~m}^{-3}\right)$ for those sites. The stronger fluxes at higher $u_{*}$ are tied to lower $w$ values. Lower $z_{0}$ (smoother surface) corresponds well to emission at lower $u_{*}$ values. Emission flux for $u_{*}>0.6$ is observed only for $w<0.06 \mathrm{~m}^{3} \mathrm{~m}^{-3}$ (with very few exceptions). At the lower end, medium roughness dominates. Occasionally, we measured vertical dust flux at sites with $w>0.06 \mathrm{~m}^{3} \mathrm{~m}^{-3}$ despite $u_{*}<0.4 \mathrm{~m} \mathrm{~s}^{-1}$ (high saltation flux at L5 under these conditions, though). The fact that the sample size is small and the inherent measurement uncertainties are large (as discussed in Sect. 2) is suggestive of an artefactual behaviour. However, observed local dust devils can pick up substantial amounts of dust which the dust tracks at $3 \mathrm{~m}$ height would easily record. The fraction of the emitted mass flux at low $u_{*}$ with respect to the total mass flux might not be significant during dust events with a high saltation flux, but the omission of frequent low dust emission below the saltation threshold can lead to measurable systematic underestimation of the dust emission flux.

In Fig. 7e and f, the roughness scheme proposed by Raupach et al. (1993) (Eq. 8) is applied. Lesser sensitivity of $u_{* \text { thr }}$ to changes in $z_{0}$ is found with this scheme. Although it spans

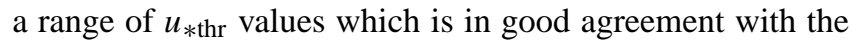
observations, it is rather insensitive to variations in aerodynamic surface roughnesses $>0.5 \mathrm{~cm}$. Given that the majority of our observed $z_{0}$ values is $<0.5 \mathrm{~cm}$, the applicability of the SH04 roughness correction scheme seems questionable, despite having selected the remaining parameters such that they fit the category for bare surfaces with dense solid obstacles.

In Fig. $8 \mathrm{~b}$ and d, Exps. $4 \mathrm{a}$ and $4 \mathrm{~b}$ are compared with observations as a function of $u_{*}$. It can be seen that $u_{* \text { thr }}$ of the vertical flux is basically insensitive to changes in roughness in the case of SH04. Rather, $u_{* t h r}$ is controlled by the soil moisture alone. Replacing it with the McK04 drag partition scheme leads to more variability and eventually better agreement with observations (results not shown). In the case of MB95, $u_{* \text { thr }}$ is equally controlled by surface roughness (Fig. 8c) and soil moisture (not shown).

The MB95 drag partition scheme relates $z_{0}$ to roughness densities of solid obstacles. A major limitation is its nonapplicability for larger obstacles. At the pan surface, large crustal plates got lifted by compressive stress due to drying of the crust material. These vertically displaced plates reached $10-20 \mathrm{~cm}$ in height, stretching over several $100 \mathrm{~m}$ in a wavelike pattern with high lateral cover. High surface roughnesses were also reported by Greeley et al. (1997) from spaceborne observations in Death Valley, USA, or by Marticorena et al. (2006) from ground-based observations in Tunisia. The ridge-induced change in roughness has been studied and shown to be important in reducing the saltation flux (Kardous et al., 2005). To account for higher roughnesses, MacKinnon et al. (2004) (McK04) corrected the MB95 scheme such that it is applicable for rougher surface conditions. In their case, the higher roughness is caused by vegetation (central Mojave Desert, USA). Hence, doubts remain as to whether the assumptions made are perfectly valid for our purposes, despite the fact that the scheme performs better than the SH04.

With regard to the soil moisture correction, both the parameterisations developed by Fécan et al. (1999) (MB95) and by Shao et al. (1996) (SH04) require the exact knowledge of the moisture in the top 1-2 cm soil layer. We consider our $0-3 \mathrm{~cm}$ moisture measurement to be representative of this layer. The key aspects regarding the sensitivity of the threshold shear velocity outlined in Sect. 4.2 are reconfirmed in Fig. 8a, b. In Exps. 1c and 4c, the sole application of the soil moisture correction tends to improve agreement between simulated and observed $u_{* \text { thr }}$ as well as the vertical emission flux (not shown). Note that both formulations (MB95 and SH04) are empirically derived and hence not universally applicable for all soil moisture conditions. As pointed out by Shao (2008), they fail to be reproducible in data sets other than those from which the formulation was initially derived.

The fact that none of the evaluated model correction schemes can be used without limitations as they struggle to reproduce the observed range of $u_{* \text { thr }}$ is attributable to two principal shortcomings. (1) The roughness correction does parameterise unevenness of the terrain, but is not designed to account for different shapes such as open cells. (2) The moisture correction does parameterise the wetness of the soil, but does not incorporate moisture-dependent chemical properties of the soil which may lead to crust formation.

\subsection{Implications for dust modelling}

Sua Pan is observed to be a major Southern Hemisphere dust source. It is therefore crucial to ensure that we not only understand the physics of the dust emission process better, but are also able to represent it in state-of-the-art model dust emission schemes. Our results suggest that there is a critical problem with the current generation of dust emission schemes, as they tend vastly to overestimate the observed fluxes. Reasons are primarily related to the fact that existing schemes cannot represent all the relevant physical processes. As stated in Sect. 4.3.1, observed small-scale surface features such as large ripples or small open cells within an otherwise crusted surface are not described in the existing schemes. Failing to include a crust leads to a higher availability of sediment in the model as, in the field, deflatable fluff material is either trapped in open cells of the crust (absorbing saltation momentum), or is buried under a thick crust. Also, the availability of coarse material is limited due to the surface characteristics. Our findings may imply that most of the 

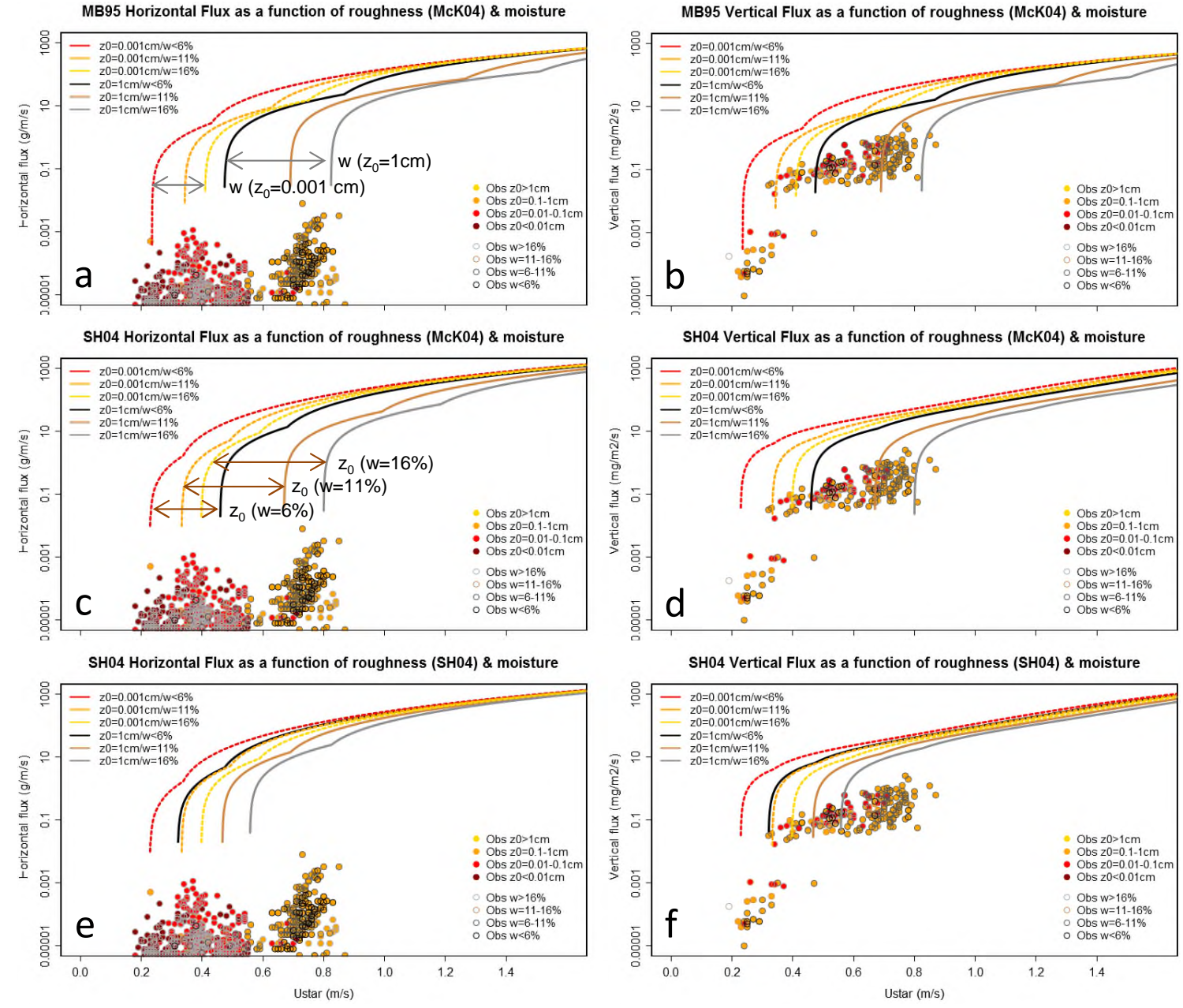

Figure 7. Horizontal and vertical emission fluxes for the baseline Exp. 1a (a, b) and Exp. 4a (c, d, e, f). The entire range of observed surface roughness and soil moisture is plotted as a function of $u_{*}$. Likewise, the observational data are split into groups of different roughnesses and moisture. Lowest observed $z_{0}$ are indicated by red and dark red dots, and highest observed $z_{0}$ by orange and yellow dots (see legend). Lowest observed $w$ are indicated by black and dark grey open circles around the dots, and higher observed $w$ by brown and light grey open circles (see legend). Modelled $z_{0}$ are set to two groups of 0.001 and $1 \mathrm{~cm}$, whereas modelled $w$ are set to three groups of 6,11 , and $16 \%$, respectively.

modelled global dust emissions are based on partly invalid assumptions.

Why - despite these limitations - are current emission schemes able to reproduce the global dust cycle fairly well? Apart from the potential counterbalancing effect of equally erroneous dry and wet deposition assumptions, the fact that global emissions are controlled by a few very productive sources which are driven by frequent and excessive exceedance of the threshold wind speeds tends to eradicate problems which occur at wind speeds just above $u_{* \text { thr }}$. For example, neither the drag partition nor the soil moisture correction will have a sizeable effect once $u_{* \text { thr }}$ is exceeded. Furthermore, the signal-to-noise-ratio increases with higher wind speeds, acting to minimise biases introduced by inaccurate representations of the surface conditions. Instead, in- variable parameters such as the soil size distribution become the dominant source of error.

Another - and perhaps the most important - reason for the acceptably good reproduction of the global dust budget is the fact that many models assume an empirical background size distribution (Zender et al., 2003) rather than modelling it explicitly. Equally important, the concept of preferential dust sources (Ginoux et al., 2001; Bullard et al., 2011) acts to nudge the models towards the observed dust emission patterns by relaxing back the threshold emission and, in essence, removing the crusting issue from the modelling process. The fact that none of the current model emission schemes is able to reproduce the spatial distribution of the major dust sources correctly without applying either of these auxiliary steps reinforces our concerns regarding the validity of the emission schemes. 


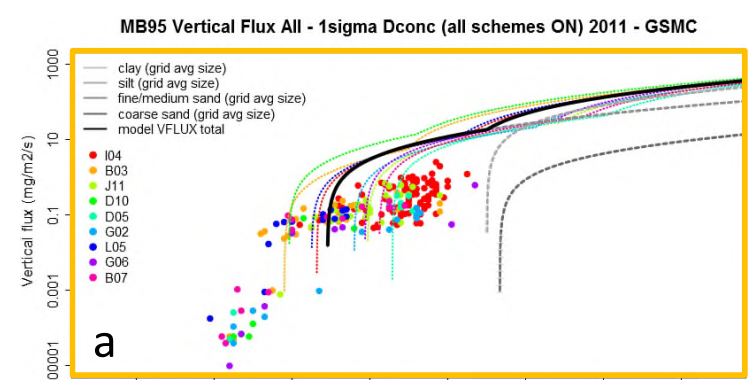

MB95 Vertical Flux All - 1sigma Dconc (moist corr OFF) 2011 - GSMC

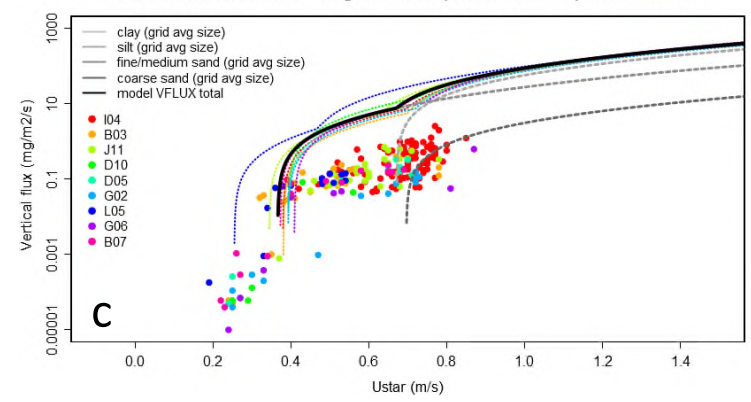

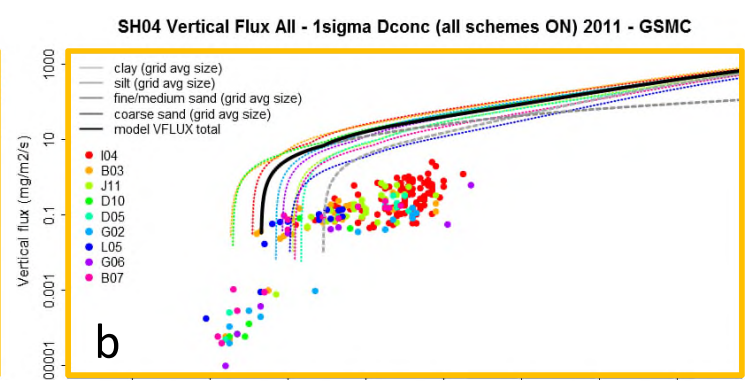

SH04 Vertical Flux All - 1sigma Dconc (moist corr OFF) 2011 - GSMC

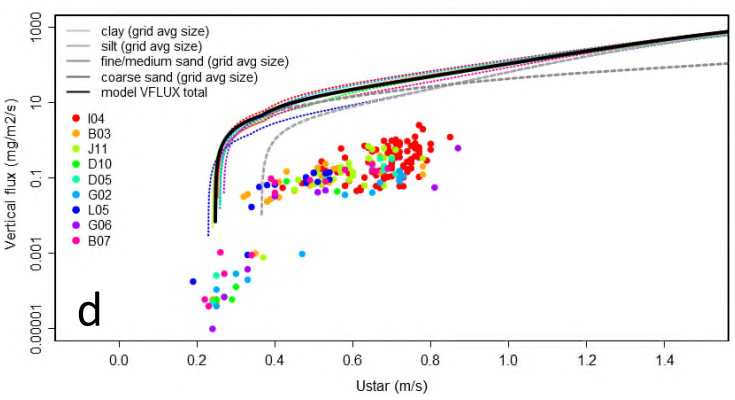

Figure 8. Vertical emission flux for Exps. 1a, b (a, c), and 4a, b (b, d). Coloured circles are the observed fluxes. The simulated grid average flux is shown in black. The fluxes of the individual field sites are complementarily given by the dotted coloured lines. The dashed grey lines refer to the model particle size categories as specified on the top left, with fine/medium sand being emitted first (compare Fig. 5).

Given the important role that surface crust seems to play, we recommend that these features be represented in the models. A crustiness parameter to correct $u_{* \text { thr }}$ could be defined as the aggregated state of the dry ground surface for resistant crusts as proposed by Ishizuka et al. (2008). Using available maps of aerodynamic surface roughness length (Prigent et al., 2005; Laurent et al., 2008), an adjusted version which takes crust cover into account may be possible. In addition, the spatio-temporal considerations can help to find an appropriate tuning constant to constrain the spatial heterogeneity. This is particularly true as only a small portion of the grid (I4 in our case) controls the bulk of the emissions. The incorporation of sub-grid scale emission schemes into climate or NWP models could be a worthwhile effort in that regard. What remains elusive so far is whether the small range of roughness and soil moisture values for which we measured dust fluxes at the grid is indicative of a systematic relation between $z_{0}, w$ and the properties of the crust.

The aspect of spatial heterogeneity is also related to model resolution. A typical grid box in a regional climate or NWP model corresponds to the size of our grid in the field $\left(12 \mathrm{~km}^{2}\right)$. One such single grid box is treated as a homogeneous surface, with soil moisture, soil size distribution and surface roughness being equal everywhere. In an ideal modelling world, not only do the grid box average values have to provide a balanced portrait of the emissive area fraction, but they also have to fit the observations of soil available for emission adequately. In the real world, most models make use of the soil texture classes after Tegen et al. (2002). In our box model experiments, the soil texture class which comes closest to our grid average size distribution is the loamy sand category. Comparing the emission flux obtained with the size distribution given by this fixed category and the observed size distribution, we find that the resulting model saltation flux is significantly reduced in the case of the fixed category. A recently published new data set of soil mineralogy for dust productive soils could alleviate the problem (Nickovic et al., 2012; Journet et al., 2014). Ideally, a correction which aims at splitting the dictated size distribution into a minimally and fully disturbed subset of data could be introduced. As it is a difficult goal to achieve, the SH04 scheme should preferentially be used as it tries to account for the shift in the size distribution, at least to some extent.

In this context, it should be noted, though, that using the fully disturbed rather than the minimally disturbed size distribution for the saltation flux calculation in our box model experiments actually reduces the resulting vertical emission flux by almost an order of magnitude, which in turn reduces the gap between model and field results considerably. Unfortunately, it happens for the wrong reason, as saltating particles do indeed consist of soil aggregates with larger particle diameters compared to what is used in NWP models. This is in accordance with other studies that have shown the size dependency of the emission flux to be important. As a result, Ishizuka et al. (2014) proposed a size-dependent power law relation and Kok et al. (2014) developed an emission parameterisation based on the brittle fragmentation theory (Kok, 2011). Both options offer another route for improvement with regard to current schemes. 
Finally, our results indicate that direct entrainment of dust particles plays a moderate role in the emission process. This assumption is based on the low correlation between simulated and observed fluxes with the tested emission schemes, particularly for the saltation flux. Although the impact of this emission mechanism is thought to be small as far as global climate simulations are concerned (since it is confined to low shear stress conditions), there is increasing evidence that sediment erosion and transport may respond effectively to wind turbulence (Weaver and Wiggs, 2011; Wiggs and Weaver, 2012). Indeed, Engelstaedter and Washington (2007) have noted that surface gustiness at dust hotspots exerts a much stronger temporal control on the timing of emissions than large-scale winds. If they are correct, direct entrainment during such gusts will very likely play a role, with concomitant effects on the global scale. Undoubtedly, direct entrainment matters for regional short-term applications (e.g. local dust storm warnings). As current schemes do not capture these aspects well, those that take stochastic effects into account (Klose and Shao, 2012, 2013) could alleviate the problem to some extent.

\section{Conclusions}

The performance of current state-of-the-art dust emission schemes has been tested against observational data retrieved during the 2011 DO4Models field campaign in Botswana. The capabilities of these schemes to describe the physical processes which are thought to play a role in the dust emission process have been explored. We have found that all models fail to reproduce the observed dust fluxes in all experiments, regardless of their level of complexity. In particular, the horizontal saltation flux is overestimated by several orders of magnitude, causing the commonly used concept of an approximately constant sandblasting mass efficiency (vertical-to-horizontal flux ratio) to break down. The main reason is that the field site is characterised by a crust of varying thickness and extension.

The current results suggest that the observed saltation flux is several orders of magnitude lower than anticipated from theoretical considerations, even at our most emissive field site. Yet the measured vertical dust emission flux is closer to theoretical expectations. We therefore infer that saltation, sandblasting and aggregate disintegration are not the only emission processes at play. Rather, these results indicate that direct dust entrainment plays a vital role too. Since none of the tested schemes accounts for direct entrainment as explicitly mentioned in Shao (2004), the discrepancy in the sandblasting efficiency is explicable. Stochastic schemes such as the one recently proposed by Klose and Shao (2012) might help to overcome this problem. We believe that our results provide a fairly robust starting point to test these emerging new schemes.
Furthermore, we have found that the most sensitive parameter for the determination of the emission threshold in the model, the soil moisture, does not always relate to the potential emissivity of the site. Some sites with low enough soil moisture values to allow for dust emission did in fact not emit owing to a thick and continuous crust. As a result, spatiotemporal variations of the emission flux are large, both in the observations and in the box model. The agreement for individual field sites is often poor, which is indeed indicative of a rather loose relationship between soil and surface properties and the resulting dust flux. The agreement between model and field data is, however, acceptable in the baseline experiments at the most emissive site. Encouragingly, the wettest site (with a smooth and thick crust) was essentially nonemissive during the 2011 field campaign.

The sensitivity experiment also taught us that even the least sensitive soil moisture correction for $u_{* t h r}$ (Fécan et al., 1999) still tends to be too sensitive. The drag partition correction for $u_{* t h r}$ is less sensitive, but only the scheme proposed by MacKinnon et al. (2004) is applicable over the entire range of observed aerodynamic surface roughnesses, despite the fact that it was originally proposed for vegetated desert surfaces. Using a minimally and a fully disturbed soil size distribution data set at each site for the model calculation of the horizontal and the vertical dust mass flux, respectively, the observed particle size range could be realistically represented by virtue of the availability of soil aggregate and soil individual particle size information.

Having systematically examined the impacts of the major emission model components, we highlight the following key findings and implications.

- Strong overestimation of saltation flux in all schemes

- Moderate overestimation of vertical flux in all schemes

- The OW64 transport scheme reduces the quantitative bias.

- Soil moisture sensitivity is too high in the Fecan scheme.

- McK04 drag partition correction outperforms MB95.

- The SH04 scheme captures observed spatial variability better.

- Vertical emission flux sensitive to soil size distribution

- Crust properties have a large impact on emitted dust mass.

- Spatio-temporal crust variability needs to be parameterised.

- The stochastic approach for direct entrainment is desirable. 
In this context, we note that an atmospheric model's meteorological fields are another key factor which may well outweigh the impact of spatio-temporal variability or measurement uncertainty (e.g. Darmenova et al., 2009; Knippertz and Todd, 2012). We address this aspect in an upcoming study using a state-of-the-art climate model.

We would like to emphasise that it is certainly necessary to include missing processes in dust emission schemes if one wants to move forward towards a more realistic description of the emission process. This is particularly true if one is aiming to provide regional or local dust emission forecasts, bearing also in mind that surface gustiness is a controlling factor for dust emission (Engelstaedter and Washington, 2007). A better constrained dust emission flux inherently helps to reduce uncertainties in other parts of the dust cycle, preferentially in the deposition flux. As many of the most emissive dust spots worldwide share common soil and surface properties, we argue that the incorporation of parameterisations which reflect mechanisms that are characteristic of crusted soils can potentially improve the overall accuracy of the models, particularly over regions which feature frequent changes between dry and wet conditions, as most monsoon regions do.

\section{The Supplement related to this article is available online at doi:10.5194/gmd-8-341-2015-supplement.}

Acknowledgements. The authors thank J. Nield, A. Dansie, and K. Vickery for their assistance in the field work. We acknowledge the support of Botswana Ash (Pty) Ltd. for help with field access and the Botswana Ministry of Environment, Wildlife and Tourism for granting permission for our research (permit no. EWT 8/36/4 XIV). We particularly thank A. Dansie for providing the soil size distribution data. We gratefully acknowledge the valuable contribution of two anonymous reviewers and, furthermore, we would like to thank H. Brindley, S. Woodward, and S. Engelstaedter for their constructive comments, all of which have helped to improve the paper a lot. The work was funded by Natural Environment Research Council grant NE/H021841/1 (DO4Models).

The Fortran code (v1.0) used to carry out the model calculations is provided as Supplement to the paper.

Edited by: H. Tost

\section{References}

Alfaro, S. C. and Gomes, L.: Modeling mineral aerosol production by wind erosion: Emission intensities and aerosol size distribution in source areas, J. Geophys. Res., 106, 18075-18084, 2001.

Alfaro, S. C., Gaudichet, A., Gomes, L., and Maillé, M.: Modeling the size distribution of a soil aerosol produced by sandblasting, J. Geophys. Res., 102, 11239-11249, 1997.
Alfaro, S. C., Gaudichet, A., Gomes, L., and Maillé, M.: Mineral aerosol production by wind erosion: Aerosol particle sizes and binding energies, Geophys. Res. Lett., 25, 991-994, 1998.

Andreae, M. O.: Climatic effects of changing atmospheric aerosol levels, Vol. 16, World Survey of Climatology, Elsevier, Amsterdam, 1996.

Ashpole, I. and Washington, R.: An automated dust detection using SEVIRI: A multiyear climatology of summertime dustiness in the central and western Sahara, J. Geophys. Res., 117, D08202, doi:10.1029/2011JD016845, 2012.

Bagnold, R. A.: The Physics of Blown Sand and Desert Dunes, Methuen, New York, 1941.

Bangert, M., Nenes, A., Vogel, B., Vogel, H., Barahona, D., Karydis, V. A., Kumar, P., Kottmeier, C., and Blahak, U.: Saharan dust event impacts on cloud formation and radiation over Western Europe, Atmos. Chem. Phys., 12, 4045-4063, doi:10.5194/acp-124045-2012, 2012.

Boucher, O., Randall, D., Artaxo, P., Bretherton, C., Feingold, G., Forster, P., Kerminen, V.-M., Kondo, Y., Liao, H., Lohmann, U., Rasch, P., Satheesh, S. K., Sherwood, S., Stevens, B., and Zhang, X.-Y.: Chapter 7: Clouds and aerosols, Tech. rep., Working Group I contribution to the IPCC 5th Assessment Report "Climate Change 2013: The Physical Science Basis", 2013.

Brindley, H. E., Knippertz, P., Ryder, C., and Ashpole, P.: A critical evaluation of the ability of the Spinning Enhanced Visible and Infrared Imager (SEVIRI) thermal infrared red-green-blue rendering to identify dust events: Theoretical analysis, J. Geophys. Res., 117, D07201, doi:10.1029/2011JD017326, 2012.

Bryant, R. G., Bigg, G. R., Mahowald, N. M., Eckardt, F. D., and Ross, S. G.: Dust emission response to climate in southern Africa, J. Geophys. Res., 112, D09207, doi:10.1029/2005JD007025, 2007.

Bullard, J. E., Harrison, S. P., Baddock, M. C., Drake, N., Gill, T. E., McTainsh, G., and Sun, Y.: Preferential dust sources: A geomorphological classification designed for use in global dust-cycle models, J. Geophys. Res., 116, F04034, doi:10.1029/2011JF002061, 2011.

Darmenova, K., Sokolik, I. N., Shao, Y., Marticorena, B., and Bergametti, G.: Development of a physically-based dust emission module within the Weather Research and Forecasting (WRF) model: Assessment of dust emission parameterizations and input parameters for source regions in Central and East Asia, J. Geophys. Res., 114, D14201, doi:10.1029/2008JD011236, 2009.

Eckardt, F. D., Bryant, R., McCulloch, G., Spiro, B., and Wood, W. W.: The hydrochemistry of a semi-arid pan basin case study: Sua Pan, Makgadikgadi, Botswana,, Appl. Geochem., 23, 15631580, doi:10.1016/j.apgeochem.2007.12.033, 2008.

Engelstaedter, S. and Washington, R.: Temporal controls on global dust emissions: The role of surface gustiness, Geophys. Res. Lett., 34, L15805, doi:10.1029/2007GL029971, 2007.

Evan, A. T., Dunion, J., Foley, J. A., Heidinger, A. K., and Velden, C. S.: New evidence for a relationship between Atlantic tropical cyclone activity and African dust outbreaks, Geophys. Res. Lett., 33, L19813, doi:10.1029/2006GL026408, 2006.

FAO-UNESCO: Soil Map of the world at 1:5000000. Volume I., Tech. rep., UNESCO, Paris, France, 1974.

Fécan, F., Marticorena, B., and Bergametti, G.: Parametrization of the increase of the aeolian erosion threshold wind friction veloc- 
ity due to soil moisture for arid and semi-arid areas, Ann. Geophys., 17, 149-157, doi:10.1007/s00585-999-0149-7, 1999.

Formenti, P., Schütz, L., Balkanski, Y., Desboeufs, K., Ebert, M., Kandler, K., Petzold, A., Scheuvens, D., Weinbruch, S., and Zhang, D.: Recent progress in understanding physical and chemical properties of African and Asian mineral dust, Atmos. Chem. Phys., 11, 8231-8256, doi:10.5194/acp-11-8231-2011, 2011.

Forster, P., Ramaswamy, V., Artaxo, P., Berntsen, T., Betts, R., Fahey, D. W., Haywood, J., Lean, J., Lowe, D. C., Myhre, G., Nganga, J., Prinn, R., Raga, G., Schulz, M., and Van Dorland, R.: Changes in Atmospheric Constituents and in Radiative Forcing, Cambridge University Press, Cambridge, UK and New York, USA, 2007.

Fryrear, D. W.: A field dust sampler, J. Soil Water Conserv., 41, 117-120, 1986.

Gillette, D.: On the production of soil wind erosion aerosols having the potential for long range transport, Journal de Recherches Atmospheriques, 8, 735-744, 1974.

Gillette, D.: A wind tunnel simulation of the erosion of soil: effect of soil texture, sandblasting, wind speed, and soil consolidation on dust production, Atmos. Environ., 12, 1735-1743, 1978.

Gillette, D. A., Fryear, D. W., Gill, T. E., Levy, T., Cahill, T. A., and Gearhart, E. A.: Relation of vertical flux of particles smaller than $10 \mathrm{~m}$ to total aeolian horizontal mass flux at Owens Lake, J. Geophys. Res., 102, 26009-26015, 1997.

Ginoux, P., Chin, M., Tegen, I., Prospero, J. M., Holben, B., Dubovik, O., and Lin, S.-J.: Sources and distribution of dust aerosols simulated with the GOCART model, J. Geophys. Res., 106, 20255-20273, 2001.

Ginoux, P., Garbuzov, D., and Hsu, N. C.: Identification of anthropogenic and natural dust sources using Moderate Resolution Imaging Spectroradiometer (MODIS) Deep Blue level 2 data, J. Geophys. Res., 115, D05204, doi:10.1029/2009JD012398, 2010.

Ginoux, P., Prospero, J. M., Gill, T. E., Hsu, N. C., and Zhao, M.: Global-scale attribution of anthropogenic and natural dust sources and their emission rates based on MODIS Deep Blue aerosol products, Rev. Geophys., 50, RG3005, doi:10.1029/2012RG000388, 2012.

Gomes, L., Rajot, J. L., Alfaro, S. C., and Gaudichet, A.: Validation of a dust production model from measurements performed in semi-arid agricultural areas of Spain and Niger, Catena, 52, 257-271, 2003.

Greeley, R. and Iversen, J. D.: Wind as a Geological Process on Earth, Mars, Venus and Titan, Cambridge University Press, New York, 1985.

Greeley, R., Blumberg, D. G., McHone, J. F., Dobrovolskis, A., Iversen, J. D., Lancaster, N., Rasmussen, K. R., Wall, S. D., and White, B. R.: Applications of spaceborne radar laboratory data to the study of aeolian processes, J. Geophys. Res., 102, 1097110983, 1997.

Haustein, K., Pérez, C., Baldasano, J. M., Jorba, O., Basart, S., Miller, R. L., Janjic, Z., Black, T., Nickovic, S., Todd, M. C., Washington, R., Müller, D., Tesche, M., Weinzierl, B., Esselborn, M., and Schladitz, A.: Atmospheric dust modeling from meso to global scales with the online NMMB/BSC-Dust model - Part 2: Experimental campaigns in Northern Africa, Atmos. Chem. Phys., 12, 2933-2958, doi:10.5194/acp-12-2933-2012, 2012.

Heinold, B., Tegen, I., Esselborn, M., Kandler, K., Knippertz, P., Müller, D., Schladitz, A., Tesche, M., Weinzierl, B., Ansmann,
A., Althausen, D., Laurent, B., Petzold, A., and Schepanski, K.: Regional Saharan Dust Modelling during the SAMUM 2006 Campaign, Tellus, 61B, 307-324, 2009.

Holben, B. N., Eck, T. F., Slutsker, I., Tanre, D., Buis, J. P., Setzer, A., Vermote, E., Reagan, J. A., Kaufman, Y. J., Nakajima, T., Lavenu, F., Jankowiak, I., and Smirnov, A.: AERONET - A federated instrument network and data archive for aerosol characterization - an overview, Remote Sens. Environ., 66, 1-16, 1998.

Huneeus, N., Schulz, M., Balkanski, Y., Griesfeller, J., Prospero, J., Kinne, S., Bauer, S., Boucher, O., Chin, M., Dentener, F., Diehl, T., Easter, R., Fillmore, D., Ghan, S., Ginoux, P., Grini, A., Horowitz, L., Koch, D., Krol, M. C., Landing, W., Liu, X., Mahowald, N., Miller, R., Morcrette, J.-J., Myhre, G., Penner, J., Perlwitz, J., Stier, P., Takemura, T., and Zender, C. S.: Global dust model intercomparison in AeroCom phase I, Atmos. Chem. Phys., 11, 7781-7816, doi:10.5194/acp-11-7781-2011, 2011.

Ishizuka, M., Mikami, M., Leys, J. F., Yamada, Y., Heidenreich, S., Shao, Y., and McTainsh, G. H.: Effects of soil moisture and dried raindroplet crust on saltation and dust emission, J. Geophys. Res., 113, D24212, doi:10.1029/2008JD009955, 2008.

Ishizuka, M., Mikami, M., Leys, J. F., Shao, Y., Yamada, Y., and Heidenreich, S.: Power law relation between sizeresolved vertical dust flux and friction velocity measured in a fallow wheat field, Aeolian Reseach, 12, 87-99, doi:10.1016/j.aeolia.2013.11.002, 2014.

Iversen, J. D. and White, B. R.: Saltation threshold on Earth, Mars and Venus, Sedimentology, 29, 111-119, 1982.

Journet, E., Balkanski, Y., and Harrison, S. P.: A new data set of soil mineralogy for dust-cycle modeling, Atmos. Chem. Phys., 14, 3801-3816, doi:10.5194/acp-14-3801-2014, 2014.

Kahn, R. A., Gaitley, B. J., Martonchik, J. V., Diner, D. J., and Crean, K. A.: Multiangle Imaging Spectroradiometer (MISR) global aerosol optical depth validation based on 2 years of coincident Aerosol Robotic Network (AERONET) observations, J. Geophys. Res., 110, D10S04, doi:10.1029/2004JD004706, 2005.

Kang, J.-Y., Yoon, S.-C., Shao, Y., and Kim, S.-W.: Comparison of vertical dust flux by implementing three dust emission schemes in WRF/Chem, J. Geophys. Res., 116, D09202, doi:10.1029/2010JD014649, 2011.

Kardous, M., Bergametti, G., and Marticorena, B.: Wind tunnel experiments on the effects of tillage ridge features on wind erosion horizontal fluxes, Ann. Geophys., 23, 3195-3206, doi:10.5194/angeo-23-3195-2005, 2005.

Kawamura, R.: Study of sand movement by wind, Tech. rep., University of California, Berkeley, CA, 1964.

King, J., Nickling, W. G., and Gillies, J. A.: Representation of vegetation and other nonerodible elements in aeolian shear stress partitioning models for predicting transport threshold, J. Geophys. Res., 110, F04015, doi:10.1029/2004JF000281, 2005.

King, J., Etyemezian, V., Sweeney, M., Buck, B. J., and Nikolich, G.: Dust emission variability at the Salton Sea, California, USA, Aeolian Research, 3, 67-79, doi:10.1016/j.aeolia.2011.03.005, 2011.

Klose, M. and Shao, Y.: Stochastic parameterization of dust emission and application to convective atmospheric conditions, Atmos. Chem. Phys., 12, 7309-7320, doi:10.5194/acp-12-73092012, 2012. 
Klose, M. and Shao, Y.: Large-eddy simulation of turbulent dust emission, Aeolian Research, 8, 49-58, doi:10.1016/j.aeolia.2012.10.010, 2013.

Knippertz, P. and Todd, M. C.: Mineral dust aerosols over the Sahara: Meteorological controls on emission and transport and implications for modeling, Rev. Geophys., 50, RG1007, doi:10.1029/2011RG000362, 2012.

Kok, J. F.: Does the size distribution of mineral dust aerosols depend on the wind speed at emission?, Atmos. Chem. Phys., 11, 1014910156, doi:10.5194/acp-11-10149-2011, 2011.

Kok, J. F., Albani, S., Mahowald, N. M., and Ward, D. S.: An improved dust emission model - Part 2: Evaluation in the Community Earth System Model, with implications for the use of dust source functions, Atmos. Chem. Phys., 14, 13043-13061, doi:10.5194/acp-14-13043-2014, 2014.

Laurent, B., Marticorena, B., Bergametti, G., and Mei, F.: Modeling mineral dust emissions from Chinese and Mongolian deserts, Global Planet. Change, 52, 121-141, 2006.

Laurent, B., Marticorena, B., Bergametti, G., Léon, J. F., and Mahowald, N. M.: Modeling mineral dust emissions from the Sahara desert using new surface properties and soil database, J. Geophys. Res., 113, D14218, doi:10.1029/2007JD009484, 2008.

Lettau, K. and Lettau, H.: Exploring the World's Driest Climate, chap. Experimental and micrometeorological field studies of dune migration, 110-147, IES Report 101, Center for Climatic Research, University of Wisconsin-Madison, 1978.

MacKinnon, D. J., Clow, G. D., Tigges, R. K., Reynolds, R. L., and Chavez Jr., P. S.: Comparison of aerodynamically and modelderived roughness lengths $\left(z_{0}\right)$ over diverse surfaces, central Mojave Desert, California, USA, Geomorphology, 63, 103-113, doi:10.1016/j.geomorph.2004.03.009, 2004.

Marticorena, B. and Bergametti, G.: Modeling the atmospheric dust cycle: 1. Design of a soil-derived dust emission scheme, J. Geophys. Res., 100, 16415-16430, 1995.

Marticorena, B., Bergametti, G., Aumont, B., Callot, Y., N'Doumé, C., and Legrand, M.: Modeling the atmospheric dust cycle: 2. Simulation of Saharan dust sources, J. Geophys. Res., 102, 43874404, 1997.

Marticorena, B., Kardous, M., Bergametti, G., Callot, Y., Chazette, P., Khatteli, H., Le Hégarat-Mascle, S., Maillé, M., Rajot, J.L., Vidal-Madjar, D., and Zribi, M.: Surface and aerodynamic roughness in arid and semiarid areas and their relation to radar backscatter coefficient, J. Geophys. Res., 111, F03017, doi:10.1029/2006JF000462, 2006.

Menut, L., Schmechtig, C., and Marticorena, B.: Sensitivity of the Sandblasting Flux Calculations to the Soil Size Distribution Accuracy, J. Atmos. Ocean. Technol., 22, 1875-1884, 2005.

Menut, L., Pérez, C., Haustein, K., Bessagnet, B., Prigent, C., and Alfaro, S.: Impact of surface roughness and soil texture on mineral dust emission fluxes modeling, J. Geophys. Res., 118, 1-16, doi:10.1002/jgrd.50313, 2013.

Nickling, W., McTainsh, G. H., and Leys, J. F.: Dust emissions from the Channel Country of western Queensland, Australia, Annals of Geomorphology, 116, 1-17, 1999.

Nickling, W., Luttmer, C., Crawley, D. M., Gillies, L. A., and Lancaster, N.: Comparison of on- and off-lake PM10 dust emissions at Owens Lake, CA, Tech. rep., Wind Erosion Laboratory, Department of Geography, University of Guelph, Ontario, Canada, 2000.
Nickling, W. G. and Gillies, J. A.: Dust emission and transport in Mali, West Africa, Sedimentology, 40, 859-868, 1993.

Nickovic, S., Vukovic, A., Vujadinovic, M., Djurdjevic, V., and Pejanovic, G.: Technical Note: High-resolution mineralogical database of dust-productive soils for atmospheric dust modeling, Atmos. Chem. Phys., 12, 845-855, doi:10.5194/acp-12-8452012, 2012.

Nield, J. M., King, J., Wiggs, G. F. S., Leyland, J., Bryant, R. G., Chiverrell, R. C., Darby, S. E., Eckardt, F. D., Thomas, D. S. G., Vircavs, L. H., and Washington, R.: Estimating aerodynamic roughness over complex surface terrain, J. Geophys. Res.Atmos., 118, 12948-12961, 2013.

Nield, J. M., Bryant, R. G., Wiggs, G. F. S., King, J., Thomas, D. S. G., Eckardt, F. D., and Washington, R.: The dynamism of salt crust patterns on playas, Geology, 43, 31-34, doi:10.1130/G36175.1, 2015.

Owen, P. R.: Saltation of uniform grains in air, J. Fluid Mech., 20, 225-242, 1964.

Pérez, C., Nickovic, S., Pejanovic, G., Baldasano, J. M., and Özsoy, E.: Interactive dust-radiation modeling: A step to improve weather forecasts, J. Geophys. Res., 111, D16206, doi:10.1029/2005JD006717, 2006.

Pérez, C., Haustein, K., Janjic, Z., Jorba, O., Huneeus, N., Baldasano, J. M., Black, T., Basart, S., Nickovic, S., Miller, R. L., Perlwitz, J. P., Schulz, M., and Thomson, M.: Atmospheric dust modeling from meso to global scales with the online NMMB/BSC-Dust model - Part 1: Model description, annual simulations and evaluation, Atmos. Chem. Phys., 11, 1300113027, doi:10.5194/acp-11-13001-2011, 2011.

Prigent, C., Tegen, I., Aires, F., Marticorena, B., and Zribi, M.: Estimation of the aerodynamic roughness length in arid and semiarid regions over the globe with the ERS scatterometer, J. Geophys. Res., 110, D09205, doi:10.1029/2004JD005370, 2005.

Rajot, J. L., Alfaro, S. C., Gomes, L., and Gaudichet, A.: Soil crusting on sandy soils and its influence on wind erosion, Catena, 53, 1-16, 2003.

Raupach, M. R.: Drag and drag partition on rough surfaces, Bound.Lay. Meteorol., 60, 375-395, 1992.

Raupach, M. R., Gillette, D. A., and Leys, J. F.: The Effect of Roughness Elements on Wind Erosion Threshold, J. Geophys. Res., 98, 3023-3029, 1993.

Redmond, H. E., Dial, K. D., and Thompson, J. E.: Light scattering and absorption by wind blown dust: Theory, measurement, and recent data, Aeolian Research, 2, 5-26, 2010.

Remer, L. A., Tanré, D., Kaufman, Y. J., Ichoku, C., Mattoo, S., Levy, R., Chu, D. A., Holben, B. N., Dubovik, O., Smirnov, A., Martins, J. V., Li, R.-R., and Ahmad, Z.: Validation of MODIS aerosol retrieval over ocean., Geophys. Res. Lett., 29, MOD3.1MOD3.4, doi:10.1029/2001GL013204, 2002.

Rice, M. A., Willetts, B. B., and McEwan, I. K.: Wind erosion of crust ed soil sediments, Earth Surf. Proc. Land., 21, 279293, doi:10.1002/(SICI)1096-9837(199603)21:3<279::AIDESP633>3.0.CO;2-A, 1996.

Shao, Y.: A model for mineral dust emission, J. Geophys. Res., 106, 20239-20254, 2001.

Shao, Y: Simplification of a dust emission scheme and comparison with data, J. Geophys. Res., 109, D10202, doi:10.1029/2003JD004372, 2004. 
Shao, Y.: Physics and Modelling of Wind Erosion, Springer Science and Business Media B. V., 2008.

Shao, Y. and Lu, H.: A simple expression for wind erosion threshold friction velocity, J. Geophys. Res., 105, 22437-22444, 2000.

Shao, Y., Raupach, M. R., and Leys, J. F.: A model for predicting Aeolian sand drift and dust entrainment on scales from paddock to region, Aust. J. Soil Res., 34, 309-342, doi:10.1071/SR9960309, 1996.

Shao, Y., Ishizuka, M., Mikami, M., and Leys, J. F.: Parameterization of size-resolved dust emission and validation with measurements, J. Geophys. Res., 116, D08203, doi:10.1029/2010JD014527, 2011a.

Shao, Y., Wyrwoll, K.-H., Chappell, A., Huang, J., Lin, Z., McTainsh, G. H., Mikami, M., Tanaka, T. Y., Wangh, X., and Yoon, S.: Dust cycle: An emerging core theme in Earth system science, Aeolian Research, 2, 181-204, 2011 b.

Sherman, D. J. and Li, B.: Predicting aeolian sand transport rates: A reevaluation of models, Aeolian Research, 3, 371-378, 2012.

Tegen, I., Harrison, S. P., Kohfeld, K., Prentice, I. C., Coe, M., and Heimann, M.: Impact of vegetation and preferential source areas on global dust aerosol: Results from a model study, J. Geophys. Res., 107, 4576, doi:10.1029/2001JD000963, 2002.

Textor, C., Schulz, M., Guibert, S., Kinne, S., Balkanski, Y., Bauer, S., Berntsen, T., Berglen, T., Boucher, O., Chin, M., Dentener, F., Diehl, T., Easter, R., Feichter, H., Fillmore, D., Ghan, S., Ginoux, P., Gong, S., Grini, A., Hendricks, J., Horowitz, L., Huang, P., Isaksen, I., Iversen, I., Kloster, S., Koch, D., Kirkevåg, A., Kristjansson, J. E., Krol, M., Lauer, A., Lamarque, J. F., Liu, X., Montanaro, V., Myhre, G., Penner, J., Pitari, G., Reddy, S., Seland, $\varnothing .$, Stier, P., Takemura, T., and Tie, X.: Analysis and quantification of the diversities of aerosol life cycles within AeroCom, Atmos. Chem. Phys., 6, 1777-1813, doi:10.5194/acp-6-1777-2006, 2006.
Wang, X., Chancellor, G., Evenstad, J., Farnsworth, J. E., Hase, A., Olson, G. M., Sreenath, A., and Agarwal, J. K.: A novel optical instrument for estimating size segregated aerosol mass concentration in real time, Aerosol Sci. Technol., 43, 939-950, 2009.

Washington, R., Bouet, B., Cautenet, G., Mackenzie, E., Ashpole, I., Engelstaedter, S., Lizcano, G., Henderson, G. M., Schepanski, K., and Tegen, I.: Dust as a tipping element: The Bodélé Depression, Chad., P. Natl. Acad. Sci., 106, 20564-20571, 2009.

Watson, J. G., Chow, J. C., Chen, L., Wang, X., Merrifield, T. M., Fine, P. M., and Barker, K.: Measurement system evaluation for upwind/downwind sampling of fugitive dust emissions, Aerosol Air Qual. Res., 11, 331-350, 2011.

Weaver, C. M. and Wiggs, G. F. S.: Field measurements of mean and turbulent airflow over a barchan sand dune, Geomorphology, 128, 32-41, 2011.

White, B. R.: Soil transport by winds on Mars, J. Geophys. Res., 84, 4643-4651, 1979.

Wiggs, G. F. S. and Weaver, C. M.: Turbulent flow structures and aeolian sediment transport over a barchan dune, Geophys. Res. Lett., 39, L05404, doi:10.1029/2012GL050847, 2012.

Zender, C. S., Bian, H., and Newman, D.: Mineral Dust Entrainment and Deposition (DEAD) model: Description and 1990s dust climatology, J. Geophys. Res., 108, 4416, doi:10.1029/2002JD002775, 2003.

Zhao, T. L., Gong, S. L., Zhang, X. Y., Abdel-Mawgoud, A., and Shao, Y. P.: An assessment of dust emission schemes in modeling east Asian dust storms, J. Geophys. Res., 111, D05S90, doi:10.1029/2004JD005746, 2006.

Zobler, L.: A world soil file for global climate modeling, Tech. rep., NASA TM-87802, 1986.

Zobler, L.: Global Soil Types, 1-Degree Grid (Zobler) data set, Tech. rep., Oak Ridge National Laboratory Distributed Active Archive Center, Oak Ridge, Tennessee, USA, 1999. 